\title{
Deficiency in AIM2 induces inflammation and adipogenesis in white adipose tissue leading to obesity and insulin resistance
}

\author{
Zhenwei Gong $^{1} \cdot$ Xinyi Zhang ${ }^{2,3,4,5} \cdot$ Kai Su $^{1} \cdot$ Ruihua Jiang $^{1} \cdot$ Zhe Sun $^{6} \cdot$ Wei Chen $^{7} \cdot$ Erick Forno $^{7} \cdot$ Eric S. Goetzman $^{8}$. \\ Jieru Wang ${ }^{7} \cdot$ H. Henry Dong ${ }^{1} \cdot$ Partha Dutta ${ }^{2,3,4} \cdot$ Radhika Muzumdar $^{1}$
}

Received: 1 March 2019 / Accepted: 11 July 2019/Published online: 11 September 2019

(C) Springer-Verlag GmbH Germany, part of Springer Nature 2019

\begin{abstract}
Aims/hypothesis Absent in melanoma 2 (AIM2) is a cytosolic sensor for double-stranded DNA and a tumour suppressor. Binding of double-stranded DNA to AIM2 forms the AIM2 inflammasome, leading to activation of caspase-1 and production of IL-1 $\beta$ and IL-18. Although inflammasome-independent effects of AIM2 have been reported, its role in energy metabolism is unknown. We aimed to evaluate the effect of AIM2 in energy metabolism and glucose homeostasis.

Methods Male and female whole body Aim 2 knockout $\left(\operatorname{Aim} 2^{-/-}\right.$) mice were used in the current study. Body weight, food intake, body composition, energy expenditure, fasting blood glucose levels, GTT and body temperature were measured at indicated time points. RNA sequencing was carried out on gonadal white adipose tissue (gWAT) in 14-month-old female mice. mRNA and protein levels in tissues were analysed by quantitative real-time PCR and immunoblot. Immune cell infiltration in gWAT was examined by flow cytometry. Stromal vascular fractions isolated from gWAT were used to investigate adipocyte differentiation. Results Male and female Aim $2^{-/-}$mice were obese compared with wild-type controls from 7 weeks of age until 51 weeks of age, with increased adiposity in both subcutaneous and visceral fat depots. While there were no differences in food intake, Aim $2^{-/}$ mice demonstrated decreased energy expenditure and impaired brown adipose tissue function compared with wild-type controls. Fasting glucose and insulin levels were elevated, and Aim $2^{-1-}$ mice were glucose intolerant on intraperitoneal GTT. RNA sequencing revealed marked upregulation of the IFN-inducible gene Ifi202b, which encodes protein 202 (p202) and elevated inflammatory signalling in gWAT of Aim $2^{-/-}$mice. Increased infiltration of total and Ly $6 \mathrm{C}^{\mathrm{low}}$ monocytes was noted at 8 weeks of age in gWAT, before the onset of obesity and insulin resistance. Ifi202b knockdown blocked adipogenesis in stromal vascular fractions and reduced inflammation in bone marrow-derived macrophages, demonstrating a key role of p202 in mediating the increased adipogenesis and inflammation in $\mathrm{Aim}^{-/-}$mice.

Conclusions/interpretation These results demonstrate a fundamental role for AIM2 in energy metabolism, inflammation and insulin resistance. Our studies establish a novel link between the innate immunity proteins, AIM2 and p202, and metabolism.
\end{abstract}

Electronic supplementary material The online version of this article (https://doi.org/10.1007/s00125-019-04983-x) contains peer-reviewed but unedited supplementary material, which is available to authorised users.

\section{Zhenwei Gong \\ Zhenwei.gong@chp.edu \\ $\triangle$ Radhika Muzumdar \\ radhika.muzumdar@chp.edu}

1 Division of Endocrinology, Department of Pediatrics, Children's Hospital of Pittsburgh of UPMC, University of Pittsburgh School of Medicine, Pittsburgh, PA 15224, USA

2 Pittsburgh Heart, Lung, Blood and Vascular Medicine Institute, University of Pittsburgh, Pittsburgh, PA, USA

3 Department of Immunology, University of Pittsburgh, Pittsburgh, PA, USA
4 Division of Cardiology, Department of Medicine, University of Pittsburgh, Pittsburgh, PA, USA

5 The 3rd Xiangya Hospital, Central South University, Changsha, Hunan, China

6 Department of Biostatistics, University of Pittsburgh Graduate School of Public Health, University of Pittsburgh, Pittsburgh, PA, USA

7 Division of Pulmonary Medicine, Department of Pediatrics, Children's Hospital of Pittsburgh of UPMC, University of Pittsburgh School of Medicine, Pittsburgh, PA, USA

8 Division of Genetics, Department of Pediatrics, Children's Hospital of Pittsburgh of UPMC, University of Pittsburgh School of Medicine, Pittsburgh, PA, USA 


\section{Research in context}

What is already known about this subject?

- Absent in melanoma 2 (AIM2) is a cytosolic receptor for double-stranded DNA

- Binding of double-stranded DNA to AIM2 activates the AIM2 inflammasome, leading to activation of caspase-1 and production of IL-1 $\beta$ and IL-18

- Ablation of receptors and key components of the inflammasome, including NOD-like receptor (NLR)P1, NLRP3, ASC, caspase- 1 and IL-1 $\beta$, protects mice from high-fat-diet-induced obesity and insulin resistance

\section{What is the key question?}

- Does AIM2 play a role in energy metabolism and glucose homeostasis?

\section{What are the new findings?}

- $\quad \operatorname{Aim} 2$ deletion induces adipogenesis and Aim2 $2^{-1-}$ mice develop spontaneous obesity and insulin resistance in both sexes. Aim $2^{-1-}$ mice also show impaired brown adipose tissue function, reduced thermogenesis and decreased energy expenditure

- $\quad$ Aim2 $2^{-1-}$ mice demonstrate increased infiltration of total and Ly $6 \mathrm{C}^{\text {low }}$ monocytes and inflammatory cytokine production in visceral fat before the onset of obesity

- The increased adipogenesis and inflammation in Aim2 $2^{-1-}$ mice is mediated through upregulation of protein 202 (p202), and knockdown of its gene (Ifi202b) blocks adipogenesis in stromal vascular fractions and reduces inflammation in bone marrow-derived macrophages

\section{How might this impact on clinical practice in the foreseeable future?}

- These findings highlight a role for the innate immune proteins AIM2 and p202 in obesity, inflammation and insulin resistance, therefore providing novel molecular targets for treating metabolic disorders

Keywords Adipogenesis · AIM2 - CX3CL1 - Ifi202b · Inflammasome · Monocyte infiltration · p202

$\begin{array}{ll}\text { Abbreviations } \\ \text { AIM2 } & \text { Absent in melanoma } 2 \\ \text { ASC } & \begin{array}{l}\text { Apoptosis-associated speck-like protein contain- } \\ \text { ing a caspase activation and recruitment domain }\end{array} \\ \text { BAT } & \text { Brown adipose tissue } \\ \text { BMM } & \text { Bone marrow-derived macrophage } \\ \text { BODIPY } & \text { Boron dipyrromethene } \\ \text { C/EBP } & \text { CCAAT/enhancer binding protein } \\ \text { CLAMS } & \text { Comprehensive Lab Animal Monitoring System } \\ \text { EE } & \text { Energy expenditure } \\ \text { FAO } & \text { Fatty acid oxidation } \\ \text { gWAT } & \text { Gonadal white adipose tissue } \\ \text { GM-CSF } & \text { Granulocyte-macrophage colony-stimulating } \\ & \text { factor } \\ \text { HFD } & \text { High-fat diet } \\ \text { HSL } & \text { Hormone-sensitive lipase } \\ \text { IBMX } & \text { 3-Isobutyl-1-methylxanthine } \\ \text { IPA } & \text { Ingenuity pathway analysis } \\ \text { LBM } & \text { Lean body mass } \\ \text { LPS } & \text { Lipopolysaccharide } \\ \text { MCP-1 } & \text { Monocyte chemoattractant protein 1 } \\ & \end{array}$

$\begin{array}{ll}\text { NLR } & \text { NOD-like receptor } \\ \text { NZO } & \text { New Zealand Obese } \\ \text { p202 } & \text { Protein 202 } \\ \text { PPAR } \gamma & \text { Peroxisome proliferator activated receptor } \gamma \\ \text { RER } & \text { Respiratory exchange ratio } \\ \text { RNAseq } & \text { RNA sequencing } \\ \text { siRNA } & \text { Small interfering RNA } \\ \text { SVF } & \text { Stromal vascular fraction } \\ \text { TBS-T } & \text { Tris-buffered saline with Tween 20 } \\ \text { TG } & \text { Triacylglycerol } \\ \text { UCP-1 } & \text { Uncoupling protein 1 } \\ \text { WAT } & \text { White adipose tissue } \\ \text { WT } & \text { Wild-type }\end{array}$

\section{Introduction}

The prevalence of obesity has markedly increased worldwide in recent decades. Fat mass expansion is mediated through increased adipocyte number (hyperplasia), adipocyte size (hypertrophy) or both [1]. Adipogenesis (cause of 
hyperplasia) is mainly governed by the transcription factors peroxisome proliferator activated receptor $\gamma(\operatorname{PPAR} \gamma)$ and the CCAAT/enhancer binding protein (C/EBP) $\alpha$, and downstream signalling pathways $[2,3]$. Decreased capacity for de novo adipogenesis coupled with an increased demand for NEFA storage in obesity leads to a switch from adipose tissue hyperplasia to hypertrophy, which contributes to insulin resistance [4].

Substantial evidence links obesity and chronic inflammation [5]. Obesity is associated with the infiltration of immune cells into the white adipose tissue (WAT), including macrophages [6, 7], dendritic cells [8], neutrophils [9, 10], and T and B cells [11-14]. WAT is a source of proinflammatory cytokines, including IL- 6 and TNF- $\alpha$, and adipokines such as leptin and adiponectin [15]. Adipose tissue immune cells produce cytokines, metalloproteinases and reactive oxygen species, causing adipose tissue dysfunction and insulin resistance [16]. The increase in immune cell infiltration is secondary to an increase in expression of chemokines in the WAT of obese individuals [17]. These chemokines, secreted from mature adipocytes, promote infiltration of monocytes in WAT, which differentiate into adipose tissue macrophages [4]. For instance, expression of fractalkine, also known as $C X 3 C L 1$, is markedly upregulated in obese human adipose tissue [18] and has been defined as an adipochemokine associated with type 2 diabetes [19].

Inflammasomes are multiprotein oligomers and an integral component of the innate immune system. They serve as receptors and sensors in the pathogen-induced innate immune response and regulate the activation of caspase- 1 through interaction with apoptosis-associated speck-like protein containing a caspase activation and recruitment domain (ASC), an inflammasome adaptor protein [20]. Upon inflammasome activation, IL-1 $\beta$ and IL-18 are released through caspase- 1 activation and subsequent cleavage of pro-IL-1 $\beta$ and IL-18 [21]. Ablation of key components of the inflammasome, such as NOD-like receptors (NLRs) including NLRP1 and NLRP3, ASC, caspase-1 and IL-1 $\beta$, protects mice from high-fat diet (HFD)-induced obesity and insulin resistance [22-24]. Neutralisation of IL- $1 \beta$ signalling using IL- $1 \beta$ antibody significantly improves glycaemic control and $\beta$-cell function in HFD-induced obesity and insulin resistance [25], indicating a role of inflammasomes in glucose homeostasis.

Absent in melanoma 2 (AIM2) belongs to the IFNinducible HIN200 domain-containing protein family [26-28]. It is a tumour suppressor and receptor of cytosolic double-stranded DNA $[29,30]$. The AIM2 inflammasome has been reported to play a role in viral infections [30-33]. In addition, the AIM2 inflammasome is also well characterised in autoimmune and inflammatory diseases such as dermatitis and arthritis and cancers $[34,35]$. A role of AIM2 in atherosclerosis through regulation of vascular muscle cell migration and inflammation $[36,37]$ was reported. To date, a direct role of AIM2 in metabolism has not yet been reported. Here, we aimed to explore the role of AIM2 in energy metabolism and glucose homeostasis using Aim 2 knockout $\left(\right.$ Aim $\left.^{-/}\right)$mice.

\section{Methods}

Mice C57B16/J wild-type (WT), Aim2 ${ }^{-1-}$ (B6.129P2$\operatorname{Aim} 2^{\mathrm{Gt}(\mathrm{CSG} 445) \mathrm{Byg} / \mathrm{J})}$ and New Zealand Obese (NZO) mice were purchased from The Jackson Laboratory (Bar Harbor, ME, USA) and bred in the animal facility at the Children's Hospital of Pittsburgh of UPMC, University of Pittsburgh School of Medicine. Aim $2^{-/-}$mice were backcrossed to C57B16/J for at least seven generations. All mice (4-5 per cage) were housed under a standard $12 \mathrm{~h}$ light/dark cycle (lights on at 07:00) with access to food and water ad libitum unless otherwise stated. For HFD-fed mice, C57B16/J mice were fed with a $60 \%$ HFD (Research Diets, New Brunswick, NJ, USA) for 4 months. Body weight and food intake were assessed weekly from 7-8 weeks of age (male and female, $n=8$ ). Body composition of mice, including fat mass and lean mass, was determined using the EchoMRI-100 system (Echo Medical Systems, Houston, TX, USA). Gonadal, perirenal and brown adipose tissue (BAT) fat pads were dissected and weighed after completion of the study. All animal studies were approved by the University of Pittsburgh Institutional Animal Care and Use Committee.

CLAMS Energy expenditure (EE), respiratory exchange ratio (RER), $\dot{V} O_{2}, \mathrm{CO}_{2}$ production and total locomotor activity were assessed by the Comprehensive Lab Animal Monitoring System (CLAMS) at room temperature (22 \pm $0.5^{\circ} \mathrm{C}$ ). In brief, mice were pre-housed in CLAMS for $24 \mathrm{~h}$ for acclimatisation, and then data were recorded for 2 days with ad libitum access to food and water. EE data were normalised to body weight. Linear regression was performed to correlate EE to lean body mass (LBM) [38].

Fasting glucose levels and IPGTT Fasting glucose levels were measured after overnight $(16 \mathrm{~h})$ fasting. For IPGTT, mice were fasted for $6 \mathrm{~h}$. After estimation of blood glucose, mice were injected with $2 \mathrm{~g} / \mathrm{kg}$ glucose intraperitoneally. Blood glucose levels were then recorded at 15, 30, 60 and $120 \mathrm{~min}$ post glucose injection.

Biochemical measurements Blood glucose was measured by glucometer (FreeStyle, Abbott Park, IL, USA) and fasting serum insulin levels were determined by UltraSensitive Mouse Insulin ELISA Kit (Crystal Chem, Elk Grove Village, IL, USA). Serum triacylglycerols (TGs) were measured using commercial kits from Thermo Fisher Scientific (Waltham, MA, USA). 
H\&E staining Gonadal WAT (gWAT) and interscapular BAT were isolated from the mice, fixed in $10 \%$ neutral buffered formalin solution overnight and transferred into $70 \%$ ethanol solution. Tissues were then embedded in paraffin for sectioning (5 $\mu \mathrm{m}$ sections) and stained with H\&E.

Adipocyte size and number quantification Quantification of adipocytes in gWAT was done using ImageJ (version $1.48 \mathrm{~V}$; https://imagej.nih.gov/ij/download.html). Images were processed as described previously [39]. Adipocytes were manually selected, and diameters were measured by ImageJ. The frequency of each diameter range was calculated as the percentage of cell counts in the range over the total cell counts.

Isolation and culture of primary stromal vascular fractions gWAT from 3-4-month-old WT and Aim $2^{-/}$mice was dissected, minced into small pieces and digested in type I collagenase for $45 \mathrm{~min}$ at $37^{\circ} \mathrm{C}$ with agitation. The digestion was stopped by adding $10 \mathrm{ml}$ growth medium containing $10 \%$ FBS and $1 \%$ penicillin and streptomycin in DMEM. The cell mixture was passed through a $70 \mu \mathrm{m}$ cell strainer and then centrifuged for $10 \mathrm{~min}$ at $250 \mathrm{~g}$. The pellets were collected, washed three times with growth medium and then seeded on $10 \mathrm{~cm}$ dishes. Medium was changed every other day.

Adipocyte differentiation and BODIPY staining The stromal vascular fractions (SVFs) were plated in 12 or 24 well plates and grown until full confluence. Two days after confluence, adipocyte differentiation was induced by adding differentiation medium containing dexamethasone $(2 \mu \mathrm{g} / \mathrm{ml}), 3$ isobutyl-1-methylxanthine (IBMX, $0.5 \mathrm{mmol} / \mathrm{l}$ ) and insulin $(2 \mu \mathrm{g} / \mathrm{ml})$ to the cells for 3 days, and changing to the growth medium for another 4 days. For boron dipyrromethene (BODIPY) staining, differentiated adipocytes were washed with PBS twice and fixed by $4 \%$ paraformaldehyde. After two rinses with PBS, cells were incubated with PBS containing $1 \mu \mathrm{g} / \mathrm{ml}$ of BODIPY at room temperature for $15 \mathrm{~min}$ in the dark. Cells were then rinsed with PBS twice and images taken using EVOS FL Color Imaging System (Life Technologies, Waltham, MA, USA).

Body temperature Body temperature of mice at basal level and under cold challenge conditions $\left(8^{\circ} \mathrm{C}\right.$ for $\left.4 \mathrm{~h}\right)$ was assessed by rectal temperature probe and digital thermometer (Physitemps Instruments, Clifton, NJ, USA).

Fatty acid oxidation in BAT ${ }^{14} \mathrm{C}$-palmitate was conjugated to BSA overnight and used at a final concentration of $125 \mu \mathrm{mol} / \mathrm{l}$ in $200 \mu \mathrm{l}$ reactions containing $100 \mathrm{mmol} / \mathrm{l} \mathrm{sucrose}, 10 \mathrm{mmol} / \mathrm{l}$ Tris- $\mathrm{HCl} \mathrm{pH} 7.4,5 \mathrm{mmol} / 1 \mathrm{KH}_{2} \mathrm{PO}_{4}, 0.2 \mathrm{mmol} / \mathrm{l}$ EDTA, $80 \mathrm{mmol} / 1 \mathrm{KCl}, 1 \mathrm{mmol} / 1 \mathrm{MgCl}_{2}, 2 \mathrm{mmol} / 1 \mathrm{~L}$-carnitine, $0.05 \mathrm{mmol} / \mathrm{l}$ coenzyme-A, $2 \mathrm{mmol} / \mathrm{l} \mathrm{ATP}, 1 \mathrm{mmol} / \mathrm{l}$ dithiothreitol and approximately $15 \mu \mathrm{g}$ freshly prepared interscapular BAT homogenate. Filter papers soaked in $1 \mathrm{~mol} / 1 \mathrm{KOH}$ were embedded into the caps of the reaction tubes. Reaction tubes were gently rotated in a $37^{\circ} \mathrm{C}$ water bath for $1 \mathrm{~h}$, then reactions were terminated by addition of perchloric acid to $0.5 \mathrm{~mol} / \mathrm{l}$. The released ${ }^{14} \mathrm{CO}_{2}$ was captured over a second hour of incubation at $37^{\circ} \mathrm{C} .{ }^{14} \mathrm{CO}_{2}$ captured on the filter papers was subjected to scintillation counting and the data normalised to protein content.

RNA extraction, RNA sequencing and real-time PCR Tissue or cell RNA was extracted using RNeasy purification kit (Qiagen, Valencia, CA, USA) following the manufacturer's instructions. First strand cDNA was synthesised from $1 \mu \mathrm{g}$ RNA using iScript cDNA Synthesis Kit (Bio-Rad, Hercules, CA, USA). RNA sequencing (RNAseq) was performed at the Genomic Core at the University of Pittsburgh. The quality of the RNAseq data was assessed by FastQC (Version 0.11.6; www.bioinformatics.babraham.ac.uk/projects/fastqc/) and aligned to the reference genome using TopHat2 (Version 2.1. 1; http://ccb.jhu.edu/software/tophat). RNAseq reads with low sequencing quality or mapping quality were filtered out. Gene expression counts were generated with featureCounts (Version 1.6.1; http://subread.sourceforge.net/) based on the results from TopHat2. Real-time PCR was carried out using TaqMan assays in a $10 \mu \mathrm{l}$ reaction mixture (Bio-Rad) containing $0.1 \mu \mathrm{l}$ first strand cDNA and $1 \mathrm{X}$ probe and primers mix (Bio-Rad). Probes were purchased from Life Technologies or Bio-Rad (see ESM Table 1 for details). Relative mRNA levels were calculated by $2^{-\Delta \Delta \mathrm{C}_{\mathrm{t}}}$ and normalised to Gapdh.

Immunoblotting Cells and tissues were homogenised in RIPA buffer $(50 \mathrm{mmol} / \mathrm{l}$ Tris $[\mathrm{pH} 7.4], 150 \mathrm{mmol} / \mathrm{l} \mathrm{NaCl}, 1 \%$ Triton $\mathrm{X}-100,0.5 \%$ SDS) containing proteinase inhibitors (Roche, Indianapolis, IN, USA) and phosphatase inhibitors. Total protein $(30 \mu \mathrm{g})$ was resolved on SDS-PAGE, then transferred to PVDF membranes. The membranes were blocked with 5\% non-fat dry milk in Tris-buffered saline $(154 \mathrm{mmol} / \mathrm{l} \mathrm{NaCl})$ with Tween 20 (TBS-T) for $1 \mathrm{~h}$ at room temperature. The membranes were incubated with primary antibodies (listed in ESM Table 2; diluted in 5\% BSA in TBS-T) overnight at $4^{\circ} \mathrm{C}$. The membranes were then washed three times with TBS-T and incubated with horseradish peroxidase (HRP)-conjugated secondary antibodies (diluted in 5\% non-fat dry milk in TBS-T) for an additional $1 \mathrm{~h}$ at room temperature. Images were taken after adding SuperSignal West Dura extended duration substrate (Thermo Fisher Scientific) to the membrane. Antibodies were pre-validated by molecular mass using positive control samples.

Bio-Plex Serum was used to examine circulating leptin, TNF- $\alpha$, IFN- $\gamma$, IL- 6 , monocyte chemoattractant protein 1 (MCP-1), IL- $1 \alpha$ and IL-1 $\beta$ using Bio-Plex (Bio-Rad) according to the manufacturer's instructions. 
Caspase-1 activity assay Total protein lysates were extracted from the adipose tissue, and caspase- 1 activity was assessed using Caspase-1 Colorimetric Assay Kit (BioVision, Milpitas, CA, USA) according to manufacturer's instructions.

Human studies The study was approved by the Institutional Review Board of the University of Pittsburgh. Informed consent was obtained from both parents, and assent was obtained from participating children. Subcutaneous adipose tissue samples were collected from a total of 33 participants aged 617 years (14 [42.4\%] female, mean age 12.5 years). After total RNA extraction, sequencing libraries were generated with Illumina TruSeq Stranded Total RNA Ribo-Zero H/M/R kits (Illumina, San Diego, CA, USA). Libraries were normalised and run on a NextSeq 500 sequencer (Illumina) at 75 cycles with 40 million reads per sample. After quality control, 3' adapter trimming and low-quality read filtering, RNAseq data were aligned to the reference human genome using TopHat2. Transcripts per kb per million (TPM) were used as proxy for gene expression level. Analysis was performed using a regression framework in DESeq2 (Version 1.24.0; https:// bioconductor.org/packages/release/bioc/html/DESeq2.html) for either BMI percentile or overweight/obesity, adjusting for age and sex.

\section{Isolation and culture of bone marrow-derived macrophages}

Both femurs were harvested and flushed through both ends on a cell strainer (filter) with a 25-gauge needle attached to a $10 \mathrm{ml}$ syringe. With a syringe plunger, flushed femur was minced on the cell strainer and washed with DMEM until all of the cells passed through the filter. After spinning down the cells, supernatant was carefully discarded, the pellet was washed twice with growth medium and cells were cultured in growth medium containing $20 \mathrm{ng} / \mathrm{ml}$ granulocytemacrophage colony-stimulating factor (GM-CSF) for at least 4 days before experiments.

Flow cytometry Two-month-old female WT and Aim $2^{-/-}$mice were euthanised and perfused thoroughly with $30 \mathrm{ml}$ ice-cold PBS through the left ventricle to remove blood from solid organs. gWAT was perfused, harvested and digested in FACS buffer (PBS containing $0.5 \%$ BSA) containing $1 \mathrm{mg} / \mathrm{ml}$ collagenase IV and $20 \mu \mathrm{l}$ HEPES at $37^{\circ} \mathrm{C}$ at $120 \mathrm{~g}$ for $45 \mathrm{~min}$. Cells were passed through a $40 \mu \mathrm{m}$ cell strainer, washed in $20 \mathrm{ml}$ FACS buffer and centrifuged $\left(4^{\circ} \mathrm{C}, 350 \mathrm{~g}, 7 \mathrm{~min}\right)$. Erythrocytes were lysed using ammonium-chloridepotassium (ACK) lysis buffer for $3 \mathrm{~min}$, and $3 \mathrm{ml} \mathrm{FACS}$ buffer was added and centrifuged. Bone marrow harvested as stated above was washed and resuspended in FACS buffer. Total viable cell numbers were obtained from the above aliquots using trypan blue (Cellgro, Corning, NY, USA). Following the harvesting of single-cell suspensions, cells were stained in FACS buffer. All antibodies used in this study were purchased from eBioscience (San Diego, CA, USA), BioLegend (San Diego, CA, USA) and BD Biosciences (San Jose, CA, USA). For mature myeloid cell analysis, monoclonal antibodies including anti-CD11b (M1/70), Ly6G (1A8), CD115 (AFS98) and Ly6C (AL-21) were used. Neutrophils were identified as $\mathrm{CD}_{11 b^{+}} \mathrm{Ly}_{6 \mathrm{G}^{+}}$, Ly6 $\mathrm{C}^{\text {low }}$ monocytes were identified as $\mathrm{CD}_{11 \mathrm{~b}^{+}} \mathrm{CD} 115^{+} \mathrm{Ly}_{6 \mathrm{C}^{\mathrm{low}}}$ and Ly6C $\mathrm{C}^{\text {high }}$ monocytes were defined as CD11 $\mathrm{b}^{+} \mathrm{CD} 115^{+} \mathrm{Ly}_{6 \mathrm{C}^{\text {high }}}$. Macrophages were identified as $\mathrm{CD} 5^{+} \mathrm{CD} 11 \mathrm{~b}^{+} \mathrm{CD}^{+} 4^{+} \mathrm{F} 4 / 80^{+}$. T cells were identified as $\mathrm{CD}_{1} 9^{-} \mathrm{CD}^{+}$and $\mathrm{B}$ cells were identified as $\mathrm{CD}_{19}{ }^{+}$. Data acquisition was performed using Fortessa Flow Cytometer (BD Biosciences). Data were analysed using FlowJo software (Tree Star, Ashland, OR, USA).

Ifi202b RNAi For knockdown of the IFN activated gene Ifi202b, which encodes protein 202 (p202), in primary SVF and bone marrow-derived macrophages (BMMs), small interfering RNA (siRNA) against mouse Ifi202b (SMARTpool) or scrambled siRNA (Dharmacon, Lafayette, CO, USA) was transfected into primary cells using Neon Electroporation (Life Technologies). For SVF, $50 \mathrm{nmol} / 1$ siRNA was transfected into $3 \times 10^{5}$ cells $(1150 \mathrm{~V}, 20 \mathrm{~ms}$, two pulses), and cells were seeded on 24 well plates for 3 days before being induced for differentiation using differentiation medium containing insulin, IBMX and dexamethasone. For BMMs, $50 \mathrm{nmol} / 1 \mathrm{siRNA}$ was transfected into $5 \times 10^{5}$ cells, seeded on 24 well plates and incubated in complete medium containing $20 \mathrm{nmol} / 1 \mathrm{GM}-\mathrm{CSF}$ before stimulating with lipopolysaccharide (LPS). Cells were harvested 48-72 h after transfection and knockdown of Ifi202b was examined by real-time PCR and western blotting.

Statistical analysis There was no criteria for exclusion of any data. The in vivo studies were done once with at least 5-6 animals in each group, and in vitro studies were done at least 3 times, with 2-3 replicates. Experimenters were blind to group assignment and outcome assessment in the in vitro studies and endpoint assays, such as real-time PCR, immunoblotting and Bio-Plex assays. All values shown are presented as means \pm SEM. Independent two-tailed $t$ test was used when comparing two groups between WT and Aim $2^{-/}$at a single time point. Two-way ANOVA was used when dynamic comparisons were made among variables. For each statistically significant $\mathrm{F}$ value observed for the main effect or interaction, a two-tailed post hoc test (Tukey's) was applied to determine individual differences between means. Difference was considered to be statistically significant when $p \leq 0.05$.

\section{Results}

Aim2 deletion causes spontaneous obesity in mice With ad libitum access to chow diet and water, both female (Fig. 1a) 
and male (ESM Fig. 1a) Aim2 ${ }^{-/-}$mice were larger than their WT counterparts from 7 to 51 weeks of age $(n=7-8$, Fig. 1b and ESM Fig. 1b) without significant change in food intake (Fig. 1c, d and ESM Fig. 1c). At 9 weeks of age, Aim2 ${ }^{-/-}$mice had similar fat mass to controls in both sexes (Fig. 1e and ESM Fig. 1d), while female Aim $2^{-/-}$mice had significantly higher LBM (Fig. 1f and ESM Fig. 1e). At 15 weeks, both female and male Aim $2^{--}$mice had significantly higher fat mass than controls (Fig. 1e and ESM Fig. 1d). The increased fat mass persisted throughout the study. LBM showed no significant differences at 15,22 or 32 weeks of age, indicating that differences in body weight from 15 weeks of age were entirely attributable to increased fat mass.

EE, RER and total locomotor activity were measured at 36 weeks of age. EE was significantly decreased in $\mathrm{Aim} 2^{-/}$ compared with controls when normalised to body weight (Fig. $1 \mathrm{~g}$ and ESM Fig. 2a). When adjusted for LBM, the difference in EE persisted in males (data not shown). On regression analysis, the positive relationship between daily total EE and LBM found in WT mice was lost in Aim $2^{-/-}$mice (Fig. 1h and ESM Fig. 2b). We found no significant changes in RER in both female and male Aim2 $2^{-/-}$mice (Fig. 1i and ESM Fig. 2c). a

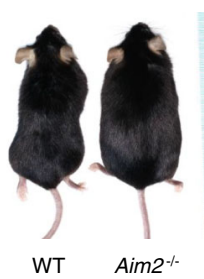

b

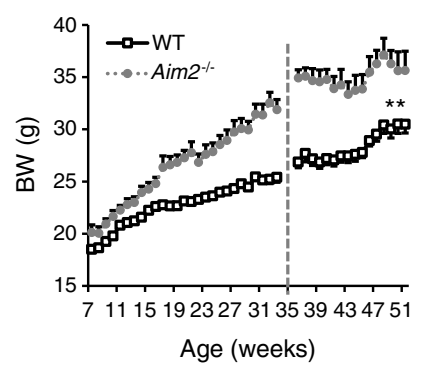

C

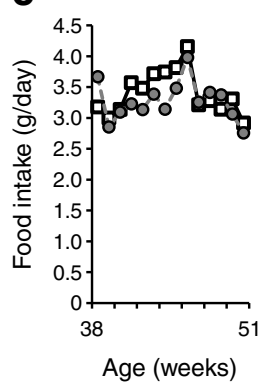

d

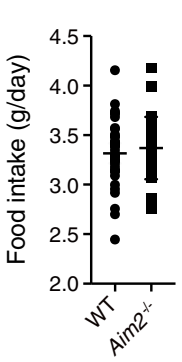

e

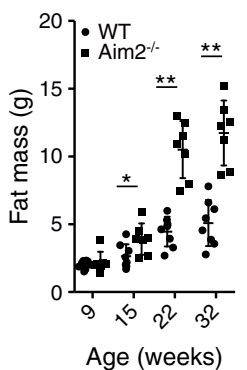

f

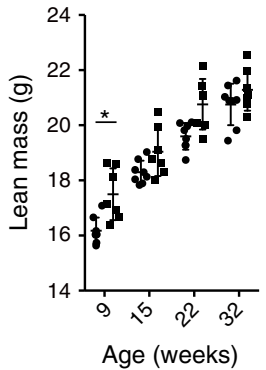

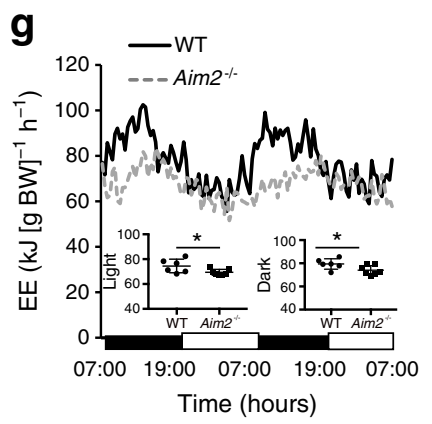

h

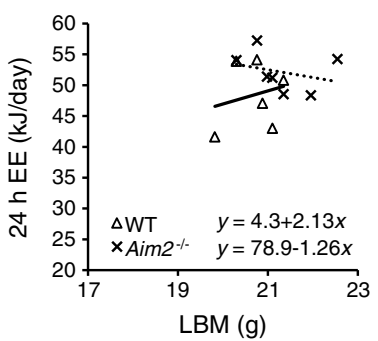

i

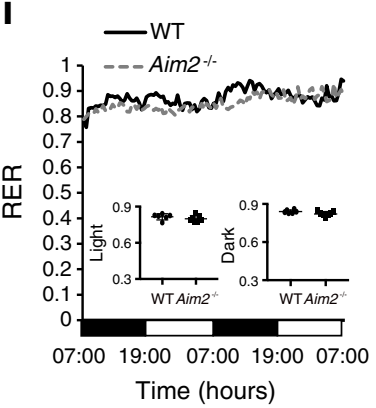

j

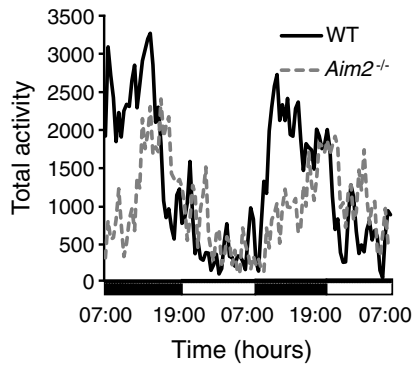

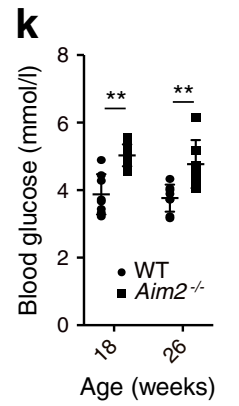
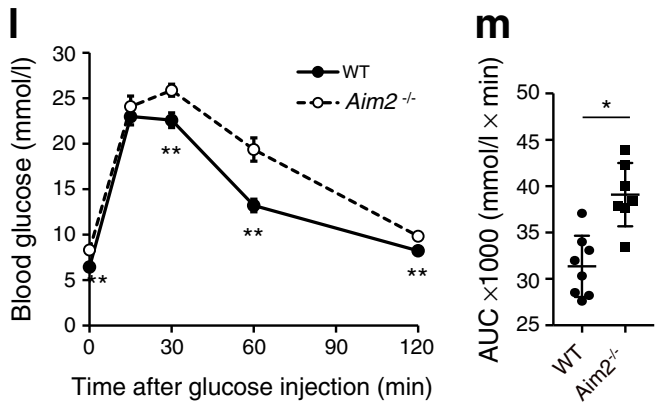

$\mathbf{0}$

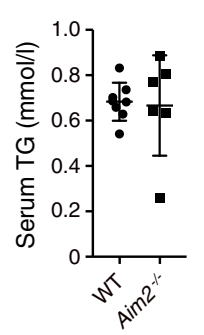

Fig. 1 Aim2 deletion induces spontaneous obesity and impaired glucose homeostasis. (a) Representative images for 14-month-old female WT and Aim $2^{-/-}$mice. (b) Body weight of female WT and Aim $2^{-/-}$mice from 7 to 51 weeks of age. The vertical dashed line represents the missing data for week of 34 and 35. (c, d) Food intake (38-51 weeks; (c) and mean food intake (7-51 weeks; (d) of the mice. The key in (b) also applies to (c). (e, f) Fat and lean mass of female WT and $\operatorname{Aim}^{-1-}$ mice at 9, 15, 22 and 32 weeks of age. The key in (e) also applies to (f). (g-j) CLAMS was used to monitor EE, RER and locomotor activity in female WT and Aim2 $2^{-1-}$ mice over a $48 \mathrm{~h}$ period: heat production (EE) over $48 \mathrm{~h}$ (mean EE [kJ [g body weight $]^{-1} \mathrm{~h}^{-1}$ ] in light and dark phases shown in the inset) (g); regression analysis of the relationship between $24 \mathrm{~h}$ total EE and LBM (h); RER in female WT and Aim $2^{-/-}$mice (mean RER in light and dark phases shown in the inset) (i); and total activity of female WT and Aim2 $2^{-/}$ mice over $48 \mathrm{~h}$ period (j). (k) Overnight fasting blood glucose levels at ages 18 and 26 weeks in WT and Aim2 $2^{-/-}$mice. $(\mathbf{l}, \mathbf{m})$ GTT (I) and AUC (m) in 8-month-old female WT and $\operatorname{Aim}^{-1-}$ mice. (n, o) Fasting insulin (n) and serum TG (o) levels in female WT and Aim $2^{-/-}$mice. Data are presented as mean \pm SEM; $n=8$ for WT and $n=7$ for $A i m 2^{-/}$mice; $*_{p}<0.05,{ }^{*} p<0.01$ by two-way ANOVA for longitudinal analysis of body weight (b) and food intake (c), and two-tailed $t$ test for analyses between two groups (where only one parameter was assessed; $(\mathbf{d}-\mathbf{g})$ and (i-o)). BW, body weight 
The total locomotor activity was significantly lower in female Aim $2^{-/-}$mice compared with WT (Fig. 1j), but no significant difference was found in males (ESM Fig. 2d).

Aim2 $2^{-/}$mice show impaired glucose homeostasis Fasting blood glucose levels were examined at 18 and 26 weeks of age after overnight fasting. Significantly higher fasting blood glucose level was noted in female Aim $2^{-/}$mice at 18 weeks of age, and was sustained at 26 weeks (Fig. 1k). In Aim $2^{-/-}$ males, significantly increased fasting blood glucose levels were noted at 26 weeks of age (ESM Fig. 3a). IPGTT showed glucose intolerance (Fig. 11 and ESM Fig. 3b) in both female and male $\mathrm{Aim}^{-/-}$mice with increased AUC for glucose (Fig. $1 \mathrm{~m}$ and ESM Fig. 3c). Fasting insulin levels (Fig. 1n and ESM Fig. 3d) were higher in male and female Aim $2^{--}$mice. Serum TG level was not significantly changed in female Aim $2^{-/}$ mice at the time of killing (Fig. 1o), while male $\mathrm{Aim}^{-/-}$mice demonstrated higher serum TG (ESM Fig. 3e).

Aim2 deletion induces adipogenesis in WAT At age 14 months, individual fat pads were significantly increased in male and female Aim $2^{-/-}$mice (Fig. 2a). Gonadal, inguinal and perirenal fat pads were all enlarged (Fig. 2b-d), and this was, at least in part, attributable to increased adipocyte size (hypertrophy) in Aim $2^{-/}$mice (Fig. 2e, f). Immunoblotting in gWAT demonstrated significantly increased levels of PPAR $\gamma$, $\mathrm{C} / \mathrm{EBP} \alpha$ and $\mathrm{C} / \mathrm{EBP} \beta$ with no changes in total and phosphorylated hormone-sensitive lipase (p-HSL; Fig. 2g, h). SVFs isolated from gWAT in 3-4-month-old mice demonstrated higher differentiation potential in Aim $2^{-/-}$mice (Fig. 2i). Real-time PCR showed increased gene expression levels of Pparg, Fasn, Glut4 (also known as Slc2a4) and Plin2 in differentiated SVF from Aim $2^{-/-}$mice (Fig. 2j-m).

Aim2 deletion induces BAT dysfunction BATs isolated from Aim $2^{-/-}$mice were larger compared with WT mice (Fig. 3a, b). H\&E staining showed larger lipid droplets in $\mathrm{Aim}^{-1}$ BAT (Fig. 3c). Fatty acid oxidation (FAO), estimated using ${ }^{14} \mathrm{C}$-labelled palmitate, was significantly decreased in BAT from Aim $2^{-/-}$mice (Fig. 3d). Core body temperature was lower in Aim $2^{-/-}$mice both basally and after $4 \mathrm{~h}$ cold exposure (Fig. 3e, f). Consistent with the defect in thermogenesis, both mRNA (Ucpl) and protein levels of uncoupling protein 1 (UCP-1) and mRNA level of Cox7al were significantly lower in $A i m 2^{-/-}$mice, whereas phosphorylation of HSL and mRNA levels of Dio2 and Prdm16 were not significantly changed (Fig. 3g-1).

Aim2 deletion upregulates proinflammatory pathway Using RNAseq, we identified 143 genes that changed more than twofold (adjusted $p<0.01$ ) in gWAT of 14-month-old female Aim $2^{-/-}$mice compared with controls (data not shown). IFNinducible genes such as Ifi202b, chemokines such as $\mathrm{Cxcl10}$
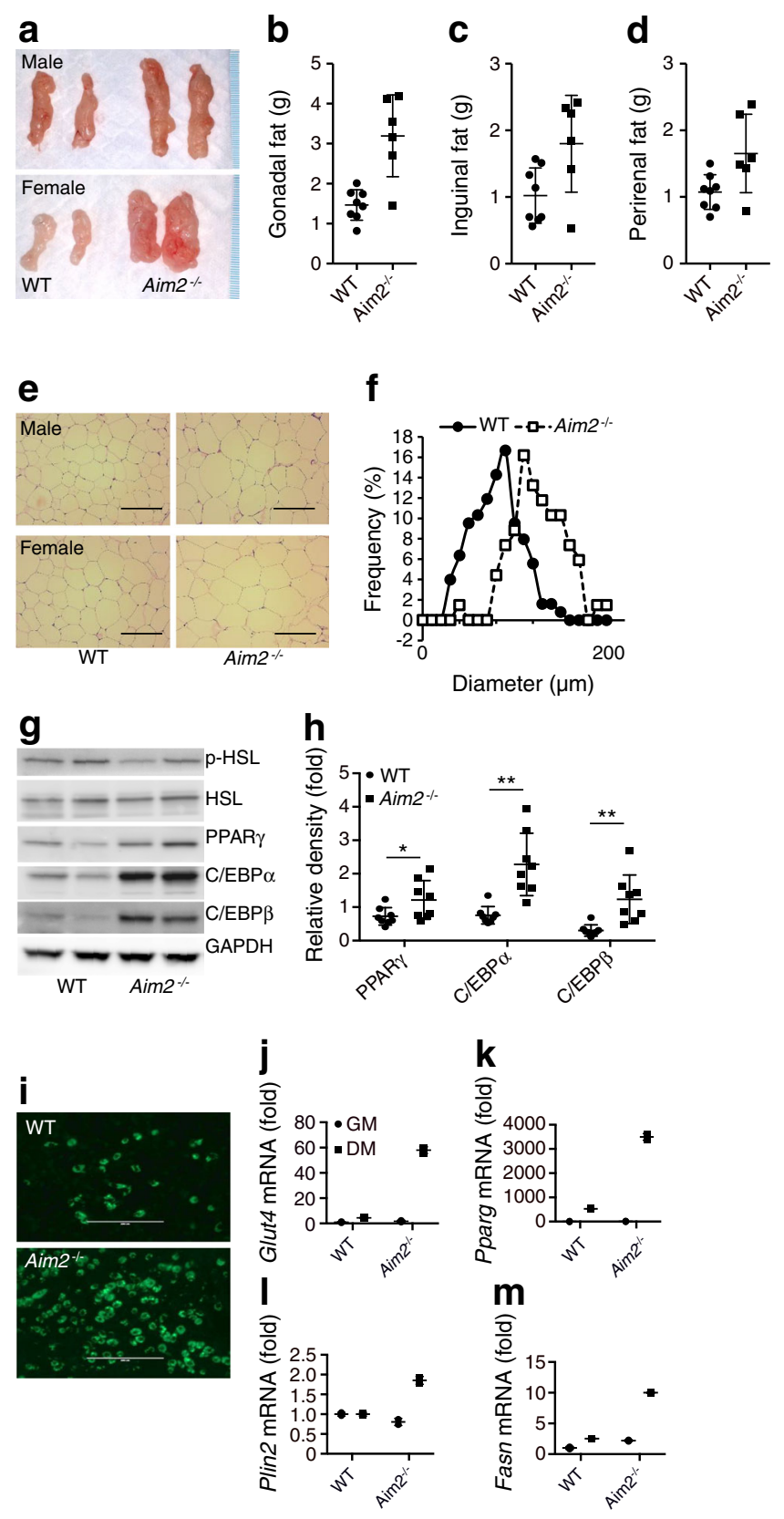

Fig. 2 Aim 2 deletion induces adipogenesis. (a) Representative images for gonadal fat in 14-month-old male and female WT and Aim $2^{-1-}$ mice. (bd) Weight of gonadal (b), inguinal (c) and perirenal (d) fat pads in female WT and Aim $2^{-/}$mice. (e, f) Representative images for H\&E staining in gWAT (e) and quantification of the frequency of adipocyte size from H\&E staining (f). Scale bars, $200 \mu \mathrm{m} . n=8$ for WT and $n=6$ for Aim $2^{-/-}$ mice. (g, h) Immunoblots (g) and quantification (h) of markers for lipolysis and adipogenesis in gonadal fat in 14-month-old female WT and Aim $2^{-/}$mice. $n=8$ for WT and $n=6$ for Aim $2^{-/-}$mice. (i-m) BODIPY staining for mature adipocytes (i), and mRNA levels for adipocyte markers Glut4 (j), Pparg (k), Plin2 (I) and Fasn (m) in differentiated SVFs isolated from 3-4-month-old WT and Aim2 $2^{-1-}$ mice. The key in (j) also applies to (k), (I) and (m). Scale bars, $400 \mu \mathrm{m}$. Data are presented as mean \pm SEM; $* p<0.05, * * p<0.01$, by two-tailed $t$ test. GAPDH, glyceraldehyde 3-phosphate dehydrogenase

and $C c l 8$, and macrophage markers such as $C d 68$ and $F 4 / 80$ (also known as Adgrel) were significantly upregulated in 

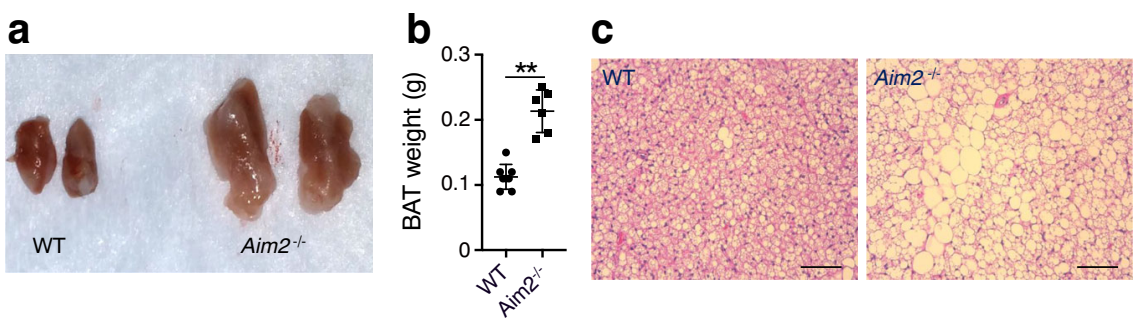

d
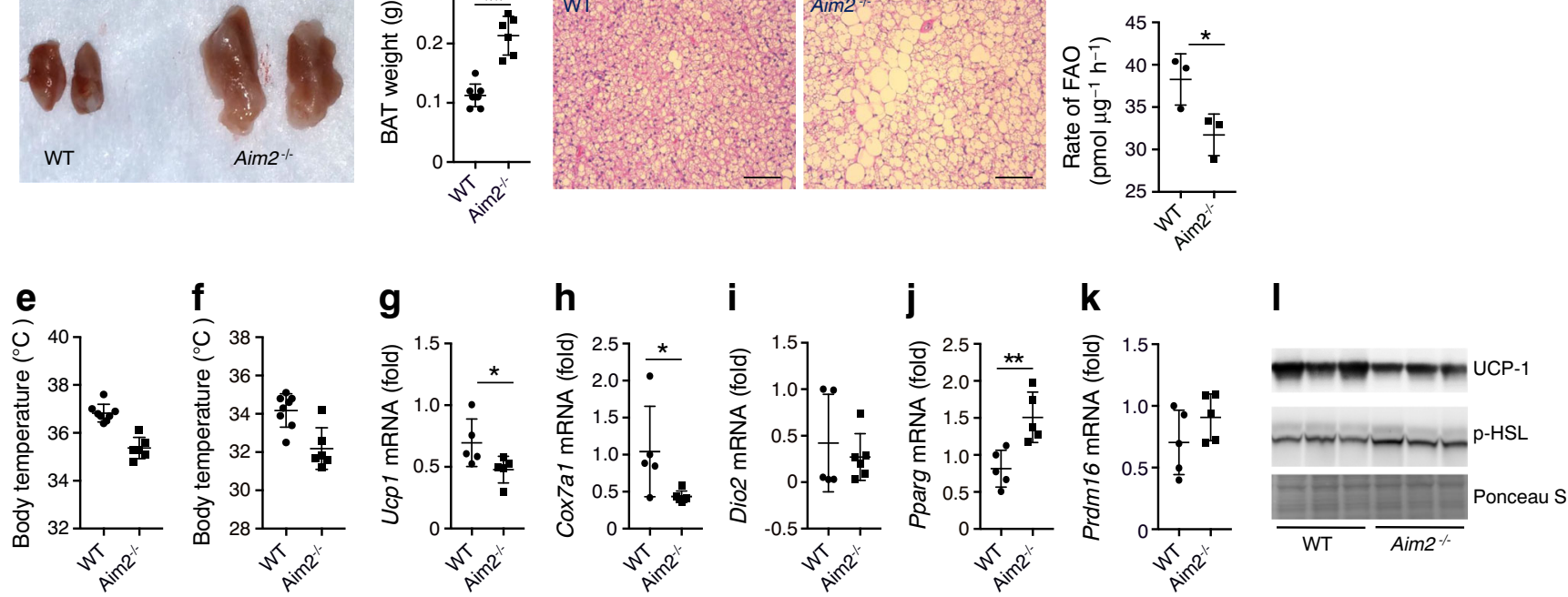

Fig. 3 Aim2 deletion induces BAT dysfunction. (a-c) Representative images (a), weight (b) and H\&E staining (c) of interscapular BAT isolated from 14-month-old female WT and Aim $2^{-/-}$mice. Scale bars, $200 \mu \mathrm{m}$. (d) Rate of FAO in homogenates of BAT isolated from 5-month-old female WT and Aim $2^{-1-}$ mice. (e, f) Core body temperature in 14-month-old female WT and Aim $2^{-/-}$mice basally (e) and after $4 \mathrm{~h}$ cold challenge

Aim $2^{-1-}$ mice (Fig. 4a). Quantitative PCR confirmed the upregulation of Ifi202b, CD5 molecule like (Cd5l), Cxcl10 and Ccl8 in Aim $2^{-1-}$ mouse gWAT (Fig. 4b-e). Ingenuity pathway analysis (IPA) revealed that most of the differentially expressed genes are involved in inflammatory and immune response signalling pathways such as IFN signalling, dendritic cell maturation and $\mathrm{T}$ cell development (Fig. 4f).

Aim2 $2^{-/}$mice show inflammation in WAT Macrophage markers were examined by PCR in 14-month-old female Aim $2^{-1}$ mice. Expression levels of CD68 and F4/80 were threefold higher in Aim $2^{-/-}$mice (Fig. 5a, b). In addition, there was a 2.5-fold higher expression level of Inos (also known as Nos2; M1 macrophage marker), but similar level of Arg1 (M2 macrophage marker), in Aim $2^{-1-}$ mice (Fig. 5c, d). The mRNA levels of Tnfa (also known as $T n f$ ) and Il6, but not $I l 18$, were significantly increased in Aim2 $2^{-/}$mice (Fig. 5e-g). Circulating leptin was increased in Aim $2^{-/}$mice (Fig. 5h), but inflammatory cytokines TNF- $\alpha$, IFN- $\gamma$, IL- $1 \alpha$ and MCP- 1 were not significantly changed (Fig. 5i-1), and IL-6 was not detectable (data not shown) in 14-month-old female Aim $2^{-1-}$ mice. Circulating IL-1 $\beta$ was also not altered by Aim 2 deletion (Fig. $5 \mathrm{~m}$ ), indicating an unchanged total inflammasomal activity in Aim $2^{-/-}$mice. Indeed, we found that basal caspase- 1 activity in Aim $2^{-1-}$ gWAT was comparable to WT controls (Fig. 5n), suggesting that metabolic changes in Aim2 $2^{-/-}$mice are independent of changes in AIM2 inflammasome activity.

Ifi202 $b$ is upregulated in obese mice and humans The mRNA and protein levels of Ifi202b, a top hit in the RNAseq study, conditions (f). (g-k) mRNA levels of Ucp1, Cox7a1, Dio2, Pparg and Prdm16 in BAT; and (l) protein levels of UCP-1 and p-HSL in BAT from 14-month-old female WT and Aim $2^{-1-}$ mice. Data are presented as mean \pm SEM; $n=8$ for WT and $n=6$ for Aim $2^{-/-}$mice; $* p<0.05$, ** $p<0.01$, by two-tailed $t$ test

were examined by both real-time PCR and immunoblot. Both mRNA and protein levels of Ifi202b were low in gWAT of 14month-old WT, and significantly increased in $A$ im $2^{-/-}$mice (Fig. 6a, e). The mRNA levels of Ifi202b were also significantly increased in BAT, bone marrow and liver (Fig. 6b-d). To examine whether high expression of Ifi202b is associated with obesity, we assessed the expression of Ifi202b in gWAT of NZO and HFD mice. We demonstrated that Ifi202b mRNA is markedly increased in both NZO and HFD mice (Fig. 6f, g). The mRNA level of IFI16, the human homologue of Ifi202b, was assessed by RNAseq in the subcutaneous adipose tissue of 33 school-aged children. We found that IFI16 expression positively correlated with BMI percentile $\left(R^{2}=0.085, p=\right.$ 0.037 after adjusting for age and sex, Fig. 6h). Overweight and obese children had significantly higher IFI16 expression than normal weight children ( $p=0.003$, Fig. 6i).

Aim2 $2^{-/-}$mice demonstrate increased monocyte infiltration in WAT prior to onset of obesity To examine whether the increased inflammation in Aim $2^{-/-}$mice occurs before onset of obesity, we characterised the immune cell infiltration in gWAT using flow cytometry in 2-month-old male WT and Aim $2^{-1-}$ mice. Immune cells were labelled in bone marrow and gWAT ( $n=6)$ using cell surface markers and gating strategies shown in Fig. 7a and ESM Fig. 4a. There was a significant increase in infiltration of total and Ly6 $\mathrm{C}^{\text {low }}$ monocytes in gWAT of Aim $2^{-1-}$ mice (Fig. 7b-d), while the macrophages, neutrophils, dendritic cells, B cells and Ly6 $\mathrm{C}^{\text {high }}$ monocytes were unchanged (Fig. 7e-j). Consistently, we found a significant increase in mRNA levels of monocyte-recruiting chemokines 

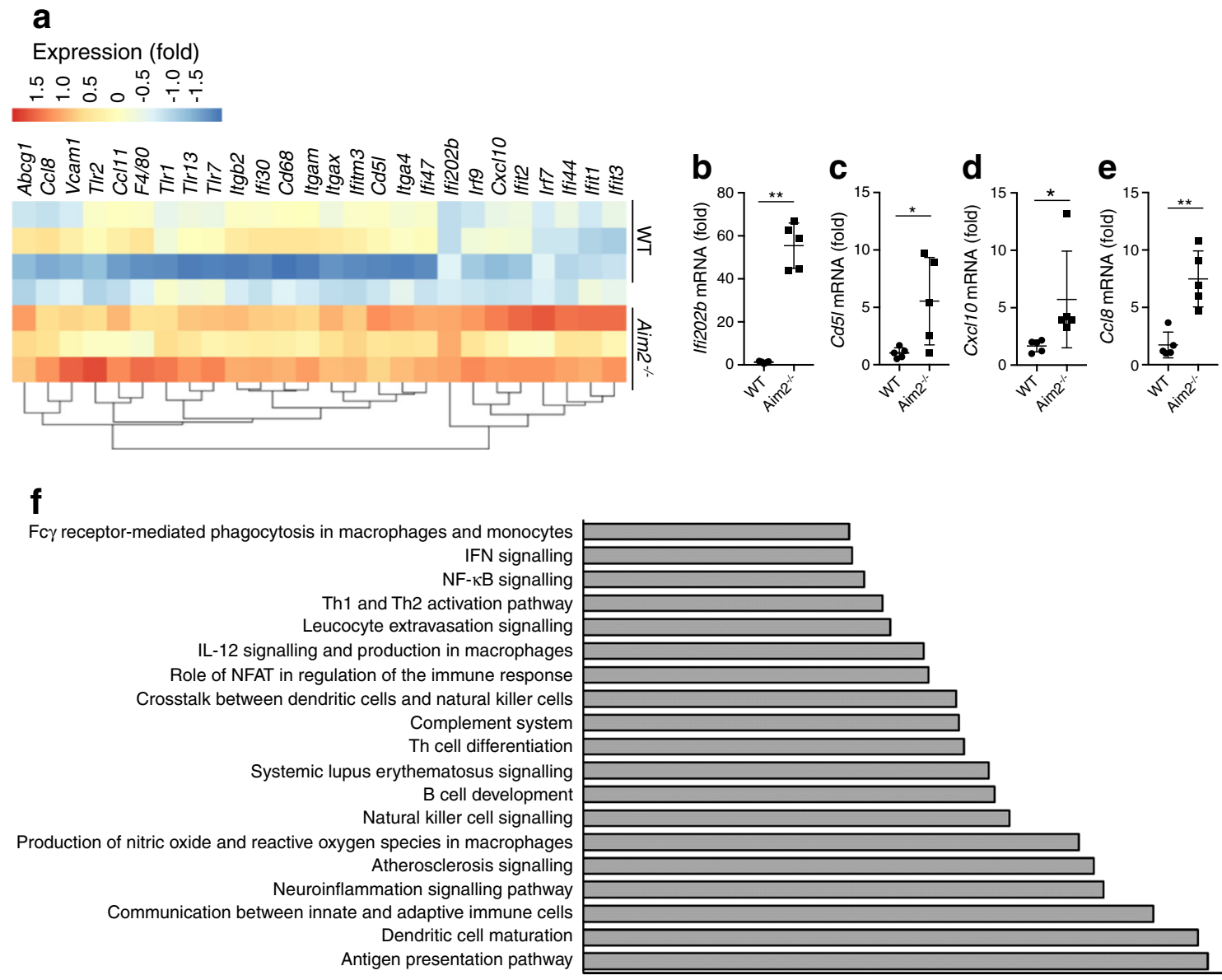

Fig. 4 RNAseq in WAT from 14-month-old WT and $\mathrm{Aim}^{-1-}$ mice. RNAseq was performed in gWAT in 14-month-old female WT and Aim $2^{-/-}$mice. (a) Heat map for inflammatory markers. (b-e) Data

including $\mathrm{Cx} 3 \mathrm{cll}, \mathrm{Ccl}$ and $\mathrm{Ccl} 3$ in gWAT of $\mathrm{Aim}^{-/-}$mice, but the $C x c l 10$ level was not significantly different $(p=0.056)$ (Fig. 7k). In bone marrow, there was a decrease in total monocytes and $\mathrm{Ly} 6 \mathrm{C}^{\text {high }}$ monocytes, and an increase in dendritic cells and macrophages, but no differences in myeloid cells, $\mathrm{T}$ cells, B cells, neutrophils and $\mathrm{Ly} 6 \mathrm{C}^{\mathrm{low}}$ monocytes in $\mathrm{Aim} 2^{-1-}$ mice (ESM Fig. 4b-k).

\section{Ifi202b knockdown blocks adipocyte differentiation in} Aim2 $2^{-/}$SVFs and inflammation in Aim2 ${ }^{-/}$BMMs To evaluate whether p202 is the key mediator for the increased adipogenesis and/or inflammation, Ifi202b was knocked down using siRNA in SVFs and BMMs isolated from 3-4-monthold male or female WT and Aim $2^{-/-}$mice. The knockdown was confirmed by PCR ( $>80 \%$ knockdown, Fig. 8 a, f). SVFs were induced for adipocyte differentiation for 7 days as detailed above. Knockdown of Ifi202b (sip202) caused significant decrease in adipocyte differentiation in SVFs isolated from Aim $2^{-/}$mice (Fig. 8b), and reduced TG levels in the media (Fig. 8c). mRNA levels of adipocyte markers Acc1

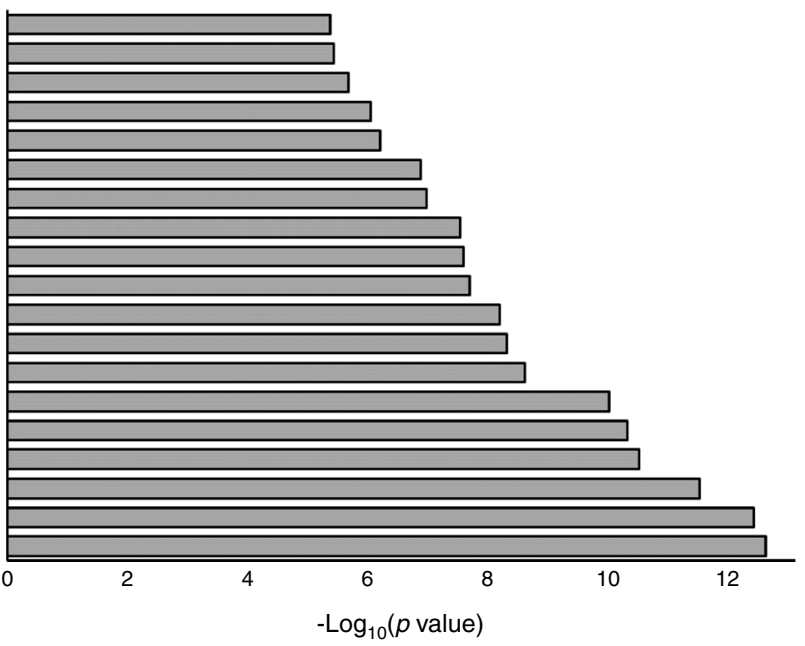

validation using real-time PCR in gonadal fat in 14-month-old female WT and $\mathrm{Aim} 2^{-/-}$mice. (f) IPA analysis. Data are presented as mean \pm SEM; $n=5 ;{ }^{*} p<0.05,{ }^{*} p<0.01$, by two-tailed $t$ test. Th, thelper

(also known as Acaca), Acc2 (Acacb), Cebpa and Fasn (Fig. $8 \mathrm{~d})$ and protein levels of fatty acid synthase (FAS), acetylCoA carboxylase (ACC), PPAR $\gamma$ and $\mathrm{C} / \mathrm{EBP} \alpha$ were decreased in the Ifi202b knockdown SVFs from Aim $2^{-1-}$ mice (Fig. 8e). In BMMs isolated from WT and $\mathrm{Aim}^{-/-}$mice, expression levels of $I L 1 b$, Il6 and Tnfa were upregulated in Aim $2^{-/}$BMMs when challenged with LPS, while knockdown of Ifi202b significantly reduced the levels of proinflammatory cytokines (Fig. 8f).

\section{Discussion}

Our data highlight a role for AIM2 protein in energy metabolism and glucose homeostasis. We show that deletion of Aim 2 results in obesity, increased inflammation in WAT and impaired glucose homeostasis. Our data also demonstrate that the obesity and insulin resistance are potentially secondary to upregulation of Ifi202b and its effects on adipogenesis and inflammation (Fig. 9). These findings are 

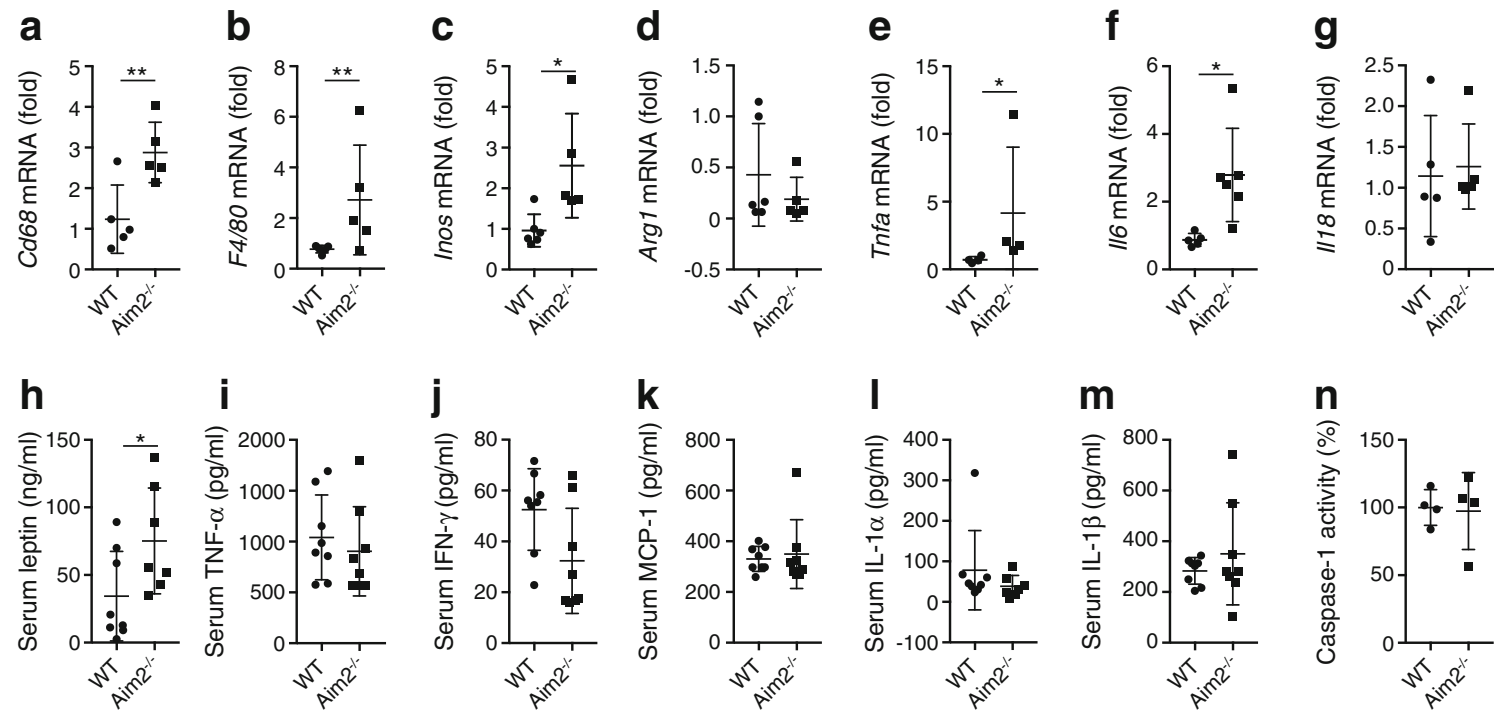

Fig. 5 AIM2 deficiency increases inflammation in WAT without affecting systemic inflammation. (a-g) mRNA levels of general macrophage markers Cd68 (a) and F4/80 (b), markers for M1 (Inos) (c) and M2 macrophages (Arg1) (d), and proinflammatory cytokines Tnfa (e), Il6 (f) and $I l 18$ (g) in gonadal fat in 14-month-old female WT and Aim2 $2^{-1}$

intriguing considering previous observations showing that deficiency of key inflammasome components, such as NLRP1, NLRP3, ASC, caspase- 1 and IL- $1 \beta$, protects mice from HFD-induced obesity and insulin resistance [22-24].
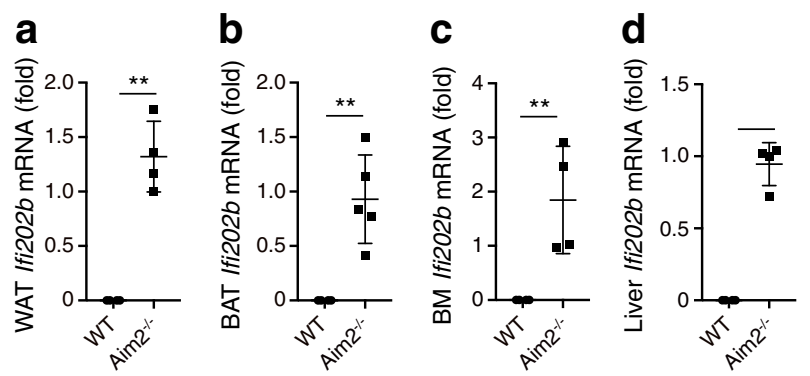

e
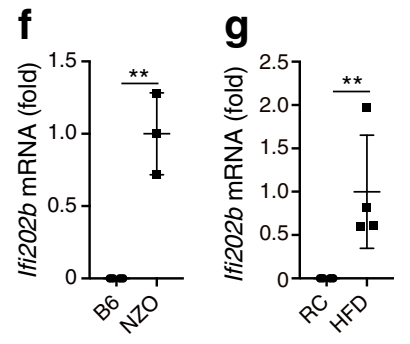

h

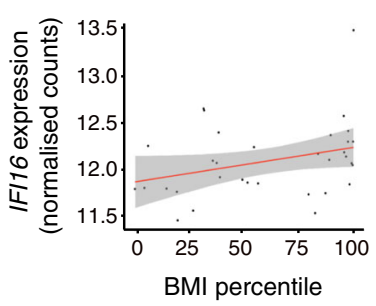

i

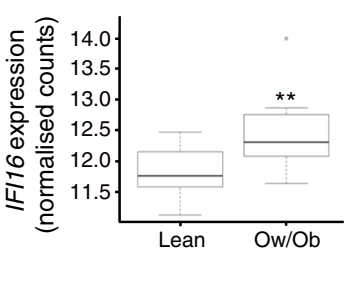

mice; $n=5$. (h-l) Serum levels of leptin (h), TNF- $\alpha$ (i), IFN- $\gamma(\mathbf{j})$, MCP-1 (k), IL-1 $\alpha$ (I) and IL-1 $\beta$ (m) in 14-month-old female WT and Aim $2^{-1-}$ mice; $n=8$ for WT and $n=7$ for Aim $2^{-/-}$mice. (n) Caspase- 1 activity in gonadal fat in WT and Aim $2^{-/-}$mice; $n=4$. Data are presented as mean \pm SEM; $* p<0.05,{ }^{* *} p<0.01$, by two-tailed $t$ test

One of the striking phenotypes of Aim2 deletion is increased body weight. The difference in body weight between Aim $2^{-/-}$and WT mice is not attributable to excess energy intake as their food intakes were similar. In fact, $\operatorname{Aim}^{-/-}$mice ate less food per day if body weight is considered. Data on EE
Fig. 6 Ifi202b/IFI16 expression is associated with obesity in rodents and humans. (a-d) mRNA levels of Ifi202b in WAT (a), BAT (b), bone marrow (BM; c) and liver (d) in 2-month-old female WT and Aim2 $2^{-1-}$ mice; $n=4$. (e) Protein level of p202 in gWAT in 14-month-old WT and Aim $2^{-/-}$mice. (f, $\left.\mathbf{g}\right)$ mRNA level of Ifi2O2b in the gonadal fat of NZO (f) and HFD (g) mice. C57B16/J mice (B6) and C57B16/J mice fed a regularchow diet (RC) were used as controls, respectively; $n=3$ for NZO/B6 and $n=4$ for HFD/RC mice. (h) Association of IFI16 expression in human subcutaneous adipose tissue with BMI percentile after adjustment for age

and sex. The regression line is shown in red and the grey shaded area shows the 95\% CI. (i) Expression of IFI16 in human subcutaneous adipose tissue in lean and overweight $(\mathrm{Ow})$ and obese $(\mathrm{Ob})$ children. The thick central line shows the median, the box encases the 25 th to 75 th percentiles, and the whiskers represent the highest and lowest non-outlier values; the one outlier in the $\mathrm{Ow} / \mathrm{Ob}$ group is indicated by the small circle. Data are presented as mean $\pm \mathrm{SEM} ;{ }^{* *} p<0.01$, by two-tailed $t$ test. GAPDH, glyceraldehyde 3-phosphate dehydrogenase 
a

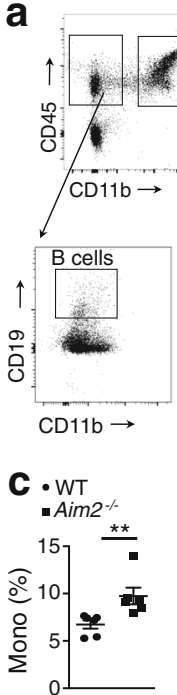

g

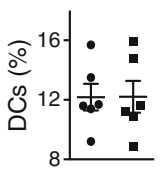

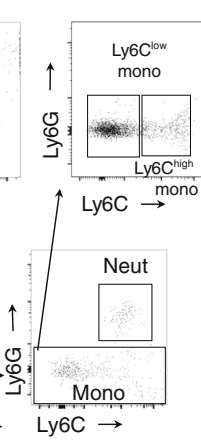

e

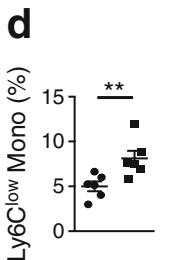

h

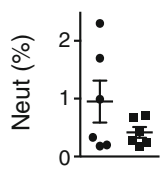

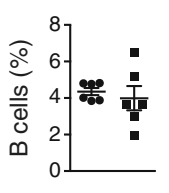

i

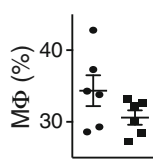

b
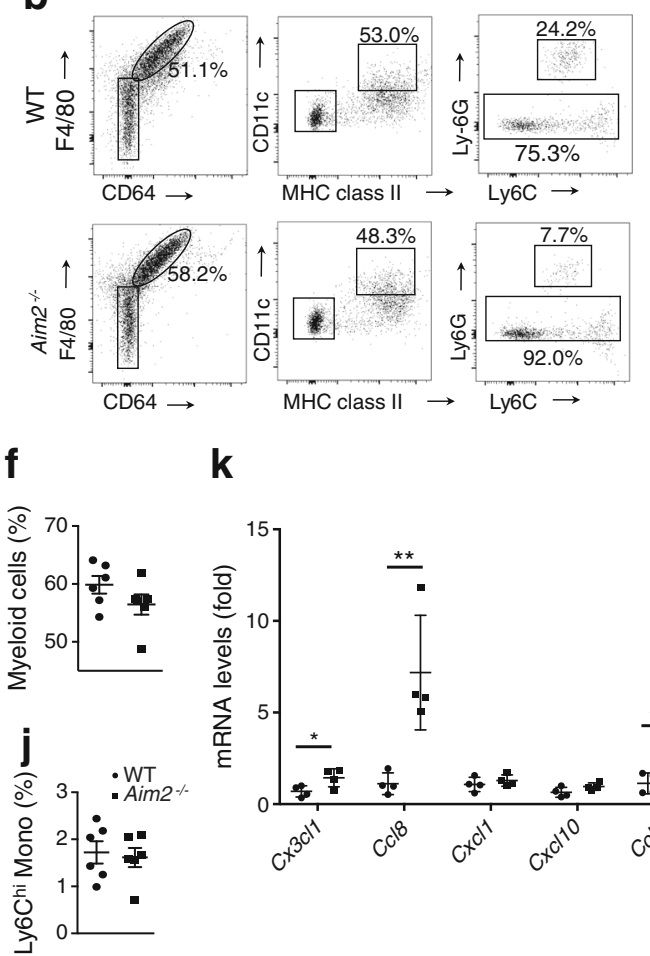

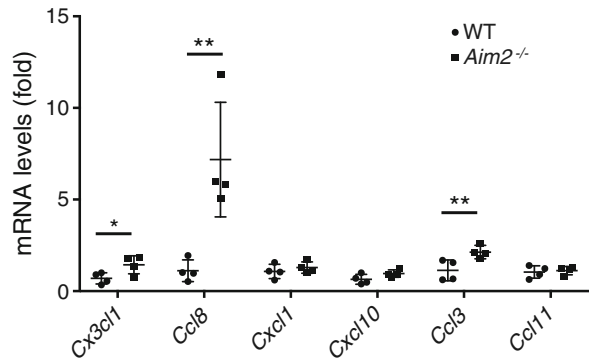

Fig. 7 Increased monocyte infiltration in gonadal WAT in Aim2 ${ }^{-/-}$mice before the onset of obesity and insulin resistance. (a) Gating strategy for flow cytometry study using SVFs from 8-week-old WT and Aim2 $2^{-1-}$ mice. Samples were gated for macrophages $\left(\mathrm{CD}^{+} 4^{+}\right.$and $\left.\mathrm{F} 4 / 80^{+}\right)$, classical DCs (MHC class II ${ }^{+}$and CD11 c ${ }^{+}$), neutrophils (Ly6G ${ }^{+}$and $\mathrm{Ly} \mathrm{C}^{\text {high }}$ ), total monocytes $\left(\mathrm{CD} 11 \mathrm{~b}^{+}, \mathrm{CD} 45^{+}\right.$and $\left.\mathrm{Ly}_{6 \mathrm{G}}^{-}\right)$, and $\mathrm{Ly}_{6 \mathrm{C}} \mathrm{C}^{\text {high }}\left(\mathrm{CD} 11 \mathrm{~b}^{+}\right.$, $\mathrm{CD}_{115^{+}}$and $\left.\mathrm{Ly} 6 \mathrm{C}^{\text {high }}\right)$ and $\mathrm{Ly}_{6 C^{\text {low }}}\left(\mathrm{CD} 11 \mathrm{~b}^{+}, \mathrm{CD} 115^{+}\right.$and $\left.\mathrm{Ly}_{6 \mathrm{C}^{\text {low }}}\right)$

suggest that at least part of the effect on obesity is mediated through a decrease in EE noted in both sexes. A decrease in EE could be secondary to dysfunction of BAT in Aim $2^{-/-}$mice as evidenced by 'paleing' of BAT on morphology and histology, as well as decreased FAO and downregulation of UCP-1. In BAT of Aim $2^{-/-}$, there is lipid accumulation instead of FAO. This is supported by the increased expression of Pparg but unchanged Prdm16, which encodes the key transcriptional factor for BAT differentiation. Furthermore, BAT dysfunction leads to defects in thermogenesis in Aim $2^{-/}$mice and thereby contributes to obesity and insulin resistance. Indeed, defects in BAT development or activity have been shown to cause obesity and the related metabolic syndrome [40], while boosting the development and function of BAT has been found to provide beneficial effects on the metabolic syndrome [41].

Adipose tissue plays a key role in energy balance, systemic metabolism and inflammation [42]. Aim $2^{-1-}$ mice have increased fat mass compared with WT controls, mediated through both hypertrophy and hyperplasia. Increased adipogenesis could be associated with increased insulin sensitivity, as seen with insulin sensitisers such as PPAR $\gamma$ agonists. However, adipogenesis along with inflammation, as seen in Aim $^{-/-}$mice, leads to the phenotype of insulin resistance. monocytes. (b) Representative images for gated macrophages, classical DCs and neutrophils. (c-j) Quantification of the percentages of different cell populations. The key in (c) also applies to $(\mathbf{d}-\mathbf{j})$. (k) Expression levels of chemokines in gonadal fat in 8-week-old WT and Aim $2^{-/-}$mice. Data are presented as mean $\pm \mathrm{SEM} ; n=6 ;{ }^{*} p<0.05,{ }^{*} p<0.01$, by two-tailed $t$ test. CDC, classical DC; DC, dendritic cell; $\mathrm{M} \Phi$, macrophage; Mono, monocyte; Neut, neutrophils

Interestingly, our data demonstrate that the immune cell infiltration of WAT precedes the onset of obesity in Aim2 $2^{-/-}$ mice. The monocyte infiltration in WAT of Aim $2^{-1-}$ mice appears to be secondary to increased expression of monocyte chemokines including $\mathrm{Ccl}, \mathrm{Ccl} 3$ and $\mathrm{Cx} 3 \mathrm{cll}$. While CCL8 and CCL3 are general chemokines for monocytes, CX3CL1 is a chemokine specifically for recruiting Ly6 $\mathrm{C}^{\text {low }}$ monocytes. Flow cytometer data confirmed the increased Ly6 $\mathrm{C}^{\text {low }}$ monocyte infiltration in gWAT of Aim $2^{-1-}$ mice. Through adoptive transfer study, Geissmann et al showed that the Ly6C $\mathrm{C}^{\text {low }}$ monocytes are recruited to noninflamed tissue and can differentiate into dendritic cells [43]. The $\mathrm{Ly} 6 \mathrm{C}^{\text {low }}$ monocytes have been shown to secrete anti-inflammatory cytokines and are likely to differentiate into M2 macrophages [44]; however, it is highly possible that monocytes and macrophages can transdifferentiate into different subsets in response to environment changes. This has been shown in models of arthritis where Ly $6 \mathrm{C}^{\text {low }}$ monocytes differentiate into proinflammatory macrophages [45]. Our data showed an increased expression level of M1 macrophage marker Inos and proinflammatory cytokines TNF- $\alpha$ and IL- 6 at 1 year of age, suggesting that the infiltrated Ly $6 \mathrm{C}^{\text {low }}$ monocytes have differentiated into proinflammatory M1 macrophages, thereby inducing 
Fig. 8 Knockdown of Ifi202b inhibits adipogenesis and inflammation in $\mathrm{Aim}^{-/-}$mice. (a) Scrambled siRNA (Scr) and sip202 were transfected into the SVF using electroporation. The mRNA level of Ifi202b was examined by real-time PCR 3 days after transfection. (b) BODIPY staining for the mature adipocytes in Scr- or sip202transfected SVFs isolated from 3 4-month-old female Aim $2^{-/-}$mice after differentiation for 7 days. Scale bars, $400 \mu \mathrm{m}$. (c-e) TG levels in the growth medium (GM) and differentiation medium (DM) (c), and mRNA levels of the adipocyte markers (d) and protein levels of adipocyte markers (e) in the undifferentiated (GM) and differentiated (DM) SVFs isolated from Aim $2^{--}$ transfected with Scr or sip202. (fi) Expression levels of Ifi2 $202 b$ and proinflammatory markers in BMMs isolated from 3-4-monthold female WT or Aim $2^{-1-}$ mice transfected with Scr or sip202. The key in (f) also applies to (g), (h) and (i). Experiments were repeated at least three times. Data are presented as mean \pm SEM; $* p<0.05, * * p<0.01$, by two-tailed $t$ test. ACC, acetyl-CoA carboxylase; FAS, fatty acid synthase
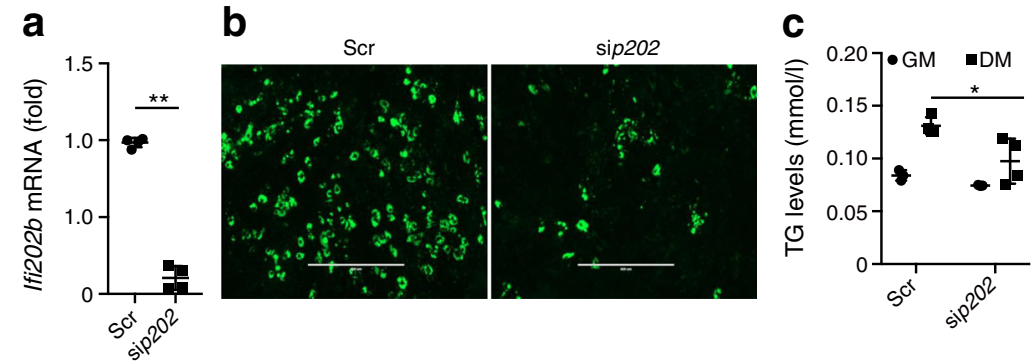

d

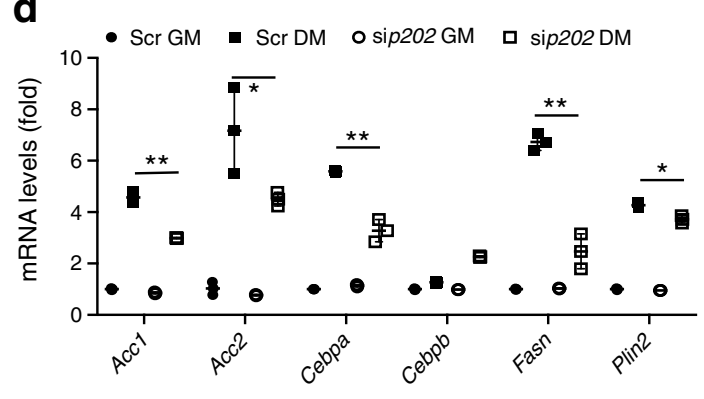

e

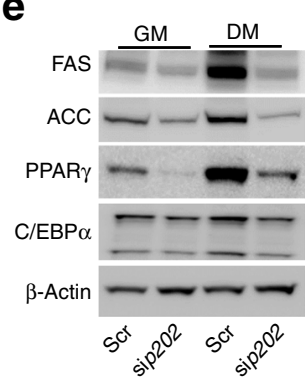

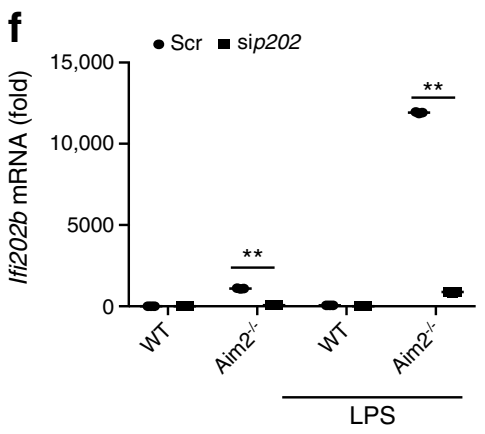
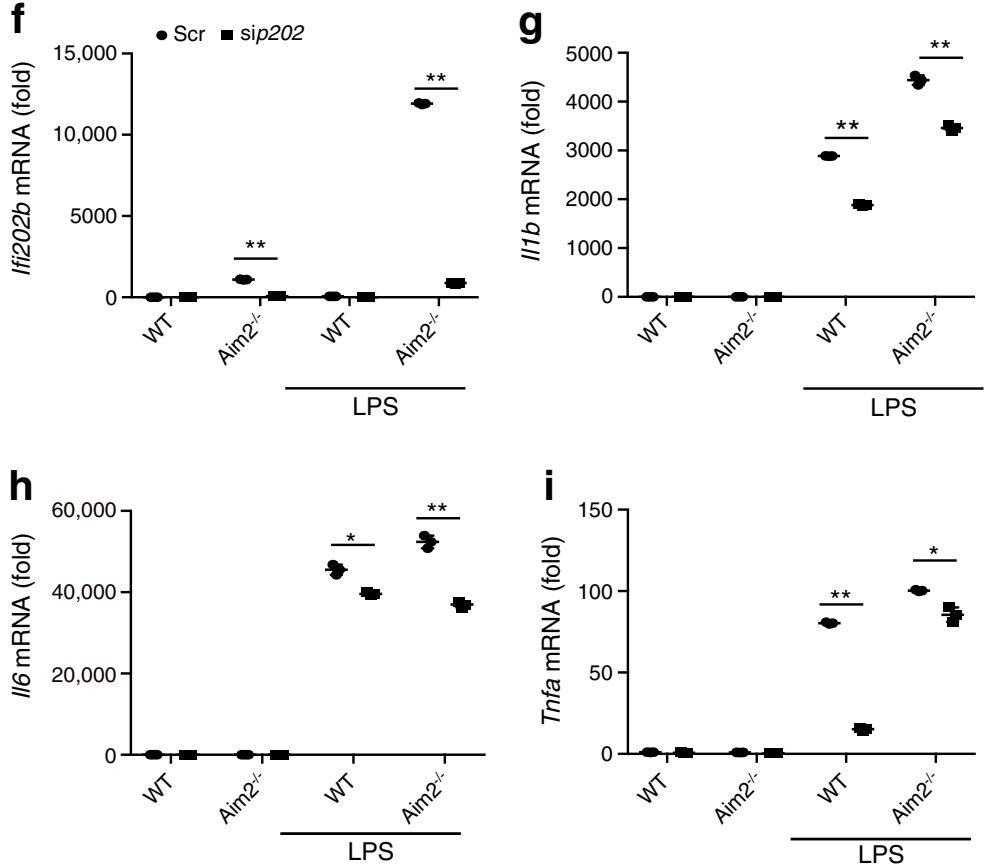

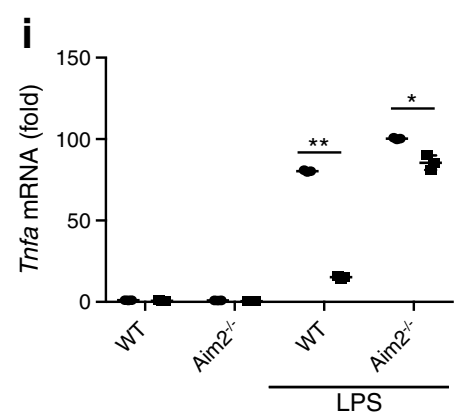

inflammation and insulin resistance. A lineage-tracing study is needed to confirm this speculation. Our observations are consistent with studies that have shown associations of expression level of CX3CL1 in both mature adipocytes and SVF in human subcutaneous adipose tissue with obesity, insulin resistance and type 2 diabetes [19].

There is an upregulation of Ifi202b in many tissues, including WAT of $A i m 2^{-/-}$mice. This is consistent with previous studies that showed increased Ifi202b in splenocytes isolated from Aim $2^{-/}$mice [46]. While Panchanathan et al showed that deletion of Aim 2 induces Ifi202b through the increase in type 1 IFNs and downstream activation of STAT1 in splenocytes [46], neither the circulating type 1 IFNs nor the expression level of local type 1 IFNs in gWAT were detectable in our study (data not shown), suggesting that alternative signalling pathway(s) regulate Ifi202b expression in the metabolic tissues in Aim $2^{-/}$mice. Previous studies have established the connection between Ifi202b and obesity [47-50]. It has been reported that $\mathrm{p} 202$ regulates adipogenesis in mouse adipose tissue-derived stem cells [51]. In addition, Ifi202b overexpression induces obesity with increased hypertrophy and decreased expression of thermogenic genes in mice [50]. These reports are consistent with our findings in $\mathrm{Aim}^{-/-}$mice, indicating a role of p202 in mediating Aim2 deletion-induced 


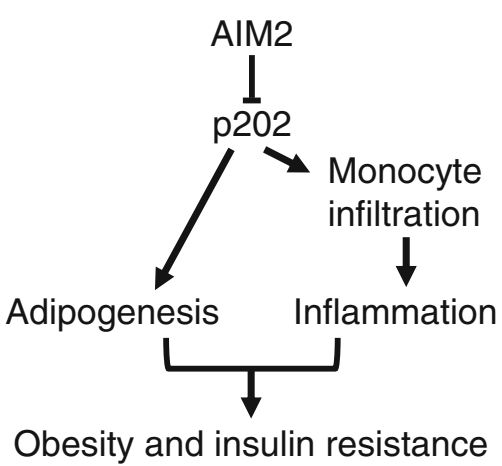

Fig. 9 Schematic illustration of the mechanism by which Aim 2 deletion induces obesity and insulin resistance

fat mass expansion. Interestingly, the expression level of IFI16 is higher in subcutaneous fat in overweight and obese children compared with control participants, and the expression level of IFI16 increases with BMI percentile in a linear regression analysis adjusted for age and sex. While increased expression of IFI16 in obese adult individuals has been reported in the visceral adipose tissue [47], our data demonstrate increased expression of IFI16 in the subcutaneous tissue of both overweight and obese school-aged children. Knockdown of Ifi2O2b in BMMs isolated from 2-month-old Aim $2^{-/-}$mice reduced the expression of proinflammatory cytokines such as $I l 1 \beta$, Il6 and Tnfa, indicating a key role for p202 in inflammation.

In summary, our findings demonstrate an inflammasomeindependent role of AIM2 in obesity and insulin resistance that is mediated through an upregulation of Ifi202b. These observations highlight a novel role for AIM2, a protein that has so far been recognised for its role in innate immunity and as a tumour suppressor, in whole body energy homeostasis. AIM2 and p202 may serve as potential drug targets for treatment of human obesity and the related metabolic syndrome.

Data availability The datasets generated during and/or analysed during the current study are available from the corresponding author on reasonable request.

Funding This work was supported in part by grants from Children's Hospital of Pittsburgh of the University of Pittsburgh Medical Center Health System (RM), CHP Foundation grants (to ZG and RM) and National Institutes of Health R00HL12076, 1R01HL143967 (to PD), 1K08HL125666 (to EF), R01HL113655 (to JW) and R01DK090242 (to ESG).

Duality of interest The authors declare that there is no duality of interest associated with this manuscript.

Contribution statement ZG and RM designed the experiments, performed statistical analysis and composed the manuscript. ZG, XZ, KS, RJ, EF, ESG, JW, HHD and PD conducted experiments, acquired and analysed data, and edited the manuscript. ZS and WC analysed the RNAseq data, conducted the bioinformatics analysis and edited the manuscript. All listed authors approved the final version of the manuscript. $\mathrm{ZG}$ and $\mathrm{RM}$ are the guarantors of this work.

\section{References}

1. Rutkowski JM, Stern JH, Scherer PE (2015) The cell biology of fat expansion. J Cell Biol 208(5):501-512. https://doi.org/10.1083/jcb. 201409063

2. Spiegelman BM, Hu E, Kim JB, Brun R (1997) PPAR gamma and the control of adipogenesis. Biochimie 79(2-3):111-112. https:// doi.org/10.1016/S0300-9084(97)81500-3

3. Rosen ED, Hsu CH, Wang X et al (2002) C/EBPalpha induces adipogenesis through PPARgamma: a unified pathway. Genes Dev 16(1):22-26. https://doi.org/10.1101/gad.948702

4. McArdle MA, Finucane OM, Connaughton RM, McMorrow AM, Roche HM (2013) Mechanisms of obesity-induced inflammation and insulin resistance: insights into the emerging role of nutritional strategies. Front Endocrinol 4:52. https://doi.org/10.3389/fendo. 2013.00052

5. Hotamisligil GS (2017) Inflammation, metaflammation and immunometabolic disorders. Nature 542(7640):177-185. https:// doi.org/10.1038/nature21363

6. Xu H, Barnes GT, Yang Q, Tan G et al (2003) Chronic inflammation in fat plays a crucial role in the development of obesity-related insulin resistance. J Clin Invest 112(12):1821-1830. https://doi.org/ 10.1172/JCI19451

7. Weisberg SP, McCann D, Desai M, Rosenbaum M, Leibel RL, Ferrante AW Jr (2003) Obesity is associated with macrophage accumulation in adipose tissue. J Clin Invest 112(12):1796-1808. https://doi.org/10.1172/JCI19246

8. Wu H, Perrard XD, Wang Q et al (2010) CD11c expression in adipose tissue and blood and its role in diet-induced obesity. Arterioscler Thromb Vasc Biol 30(2):186-192. https://doi.org/10. 1161/ATVBAHA.109.198044

9. Elgazar-Carmon V, Rudich A, Hadad N, Levy R (2008) Neutrophils transiently infiltrate intra-abdominal fat early in the course of high-fat feeding. J Lipid Res 49(9):1894-1903. https:// doi.org/10.1194/jlr.M800132-JLR200

10. Talukdar S, Oh DY, Bandyopadhyay G et al (2012) Neutrophils mediate insulin resistance in mice fed a high-fat diet through secreted elastase. Nat Med 18(9):1407-1412. https://doi.org/10.1038/nm. 2885

11. Nishimura S, Manabe I, Nagasaki M et al (2009) $\mathrm{CD} 8^{+}$effector T cells contribute to macrophage recruitment and adipose tissue inflammation in obesity. Nat Med 15(8):914-920. https://doi.org/10. 1038/nm.1964

12. Lumeng CN, Maillard I, Saltiel AR (2009) T-ing up inflammation in fat. Nat Med 15(8):846-847. https://doi.org/10.1038/nm0809846

13. Feuerer M, Herrero L, Cipolletta D et al (2009) Lean, but not obese, fat is enriched for a unique population of regulatory $\mathrm{T}$ cells that affect metabolic parameters. Nat Med 15(8):930-939. https://doi. org/10.1038/nm.2002

14. Winer DA, Winer S, Shen L et al (2011) B cells promote insulin resistance through modulation of $\mathrm{T}$ cells and production of pathogenic IgG antibodies. Nat Med 17(5):610-617. https://doi.org/10. $1038 /$ nm. 2353

15. Kershaw EE, Flier JS (2004) Adipose tissue as an endocrine organ. J Clin Endocrinol Metab 89(6):2548-2556. https://doi.org/10.1210/ jc.2004-0395

16. Guzik TJ, Skiba DS, Touyz RM, Harrison DG (2017) The role of infiltrating immune cells in dysfunctional adipose tissue. Cardiovasc Res 113(9):1009-1023. https://doi.org/10.1093/cvr/ cvx 108

17. Tourniaire F, Romier-Crouzet B, Lee JH et al (2013) Chemokine expression in inflamed adipose tissue is mainly mediated by NFkB. PLoS One 8(6):e66515. https://doi.org/10.1371/journal.pone. 0066515 
18. Shah R, Lu Y, Hinkle CC et al (2009) Gene profiling of human adipose tissue during evoked inflammation in vivo. Diabetes 58(10):2211-2219. https://doi.org/10.2337/db09-0256

19. Shah R, Hinkle CC, Ferguson JF et al (2011) Fractalkine is a novel human adipochemokine associated with type 2 diabetes. Diabetes 60(5):1512-1518. https://doi.org/10.2337/db10-0956

20. Prochnicki T, Latz E (2017) Inflammasomes on the crossroads of innate immune recognition and metabolic control. Cell Metab 26(1):71-93. https://doi.org/10.1016/j.cmet.2017.06.018

21. Man SM, Karki R, Kanneganti TD (2016) AIM2 inflammasome in infection, cancer, and autoimmunity: role in DNA sensing, inflammation, and innate immunity. Eur J Immunol 46(2):269-280. https://doi.org/10.1002/eji.201545839

22. Murphy AJ, Kraakman MJ, Kammoun HL et al (2016) IL-18 Production from the NLRP1 inflammasome prevents obesity and metabolic syndrome. Cell Metab 23(1):155-164. https://doi.org/10. 1016/j.cmet.2015.09.024

23. Stienstra R, van Diepen JA, Tack CJ et al (2011) Inflammasome is a central player in the induction of obesity and insulin resistance. Proc Natl Acad Sci U S A 108(37):15324-15329. https://doi.org/10. 1073/pnas.1100255108

24. Vandanmagsar B, Youm YH, Ravussin A et al (2011) The NLRP3 inflammasome instigates obesity-induced inflammation and insulin resistance. Nat Med 17(2):179-188. https://doi.org/10.1038/nm. 2279

25. Osborn O, Brownell SE, Sanchez-Alavez M, Salomon D, Gram H, Bartfai T (2008) Treatment with an Interleukin 1 beta antibody improves glycemic control in diet-induced obesity. Cytokine 44(1):141-148. https://doi.org/10.1016/j.cyto.2008.07.004

26. DeYoung KL, Ray ME, Su YA et al (1997) Cloning a novel member of the human interferon-inducible gene family associated with control of tumorigenicity in a model of human melanoma. Oncogene 15(4):453-457. https://doi.org/10.1038/sj.onc.1201206

27. Cresswell KS, Clarke CJP, Jackson JT, Darcy PK, Trapani JA, Johnstone RW (2005) Biochemical and growth regulatory activities of the HIN-200 family member and putative tumor suppressor protein, AIM2. Biochem Biophys Res Commun 326(2):417-424. https://doi.org/10.1016/j.bbrc.2004.11.048

28. Chen IF, Ou-Yang F, Hung JY et al (2006) AIM2 suppresses human breast cancer cell proliferation in vitro and mammary tumor growth in a mouse model. Mol Cancer Ther 5(1):1-7. https://doi.org/10. 1158/1535-7163.MCT-05-0310

29. Roberts TL, Idris A, Dunn JA et al (2009) HIN-200 proteins regulate caspase activation in response to foreign cytoplasmic DNA. Science 323(5917):1057-1060. https://doi.org/10.1126/science. 1169841

30. Hornung V, Ablasser A, Charrel-Dennis M et al (2009) AIM2 recognizes cytosolic dsDNA and forms a caspase-1-activating inflammasome with ASC. Nature 458(7237):514-518. https://doi. org/10.1038/nature 07725

31. Rathinam VA et al (2010) The AIM2 inflammasome is essential for host defense against cytosolic bacteria and DNA viruses. Nat Immunol 11(5):395-402. https://doi.org/10.1038/ni.1864

32. Strittmatter GE, Sand J, Sauter M et al (2016) IFN- $\gamma$ primes keratinocytes for HSV-1-induced inflammasome activation. J Invest Dermatol 136(3):610-620. https://doi.org/10.1016/j.jid. 2015.12.022

33. Zhang H, Luo J, Alcorn JF et al (2017) AIM2 inflammasome is critical for influenza-induced lung injury and mortality. J Immunol 198(11):4383-4393. https://doi.org/10.4049/jimmunol.1600714
34. Man SM, Zhu Q, Zhu L et al (2015) Critical role for the DNA sensor AIM2 in stem cell proliferation and cancer. Cell 162(1): 45-58. https://doi.org/10.1016/j.cell.2015.06.001

35. Wilson JE, Petrucelli AS, Chen L et al (2015) Inflammasomeindependent role of AIM2 in suppressing colon tumorigenesis via DNA-PK and Akt. Nat Med 21(8):906-913. https://doi.org/10. 1038/nm.3908

36. Pan J, Han L, Guo J et al (2018) AIM2 accelerates the atherosclerotic plaque progressions in ApoE-/- mice. Biochem Biophys Res Commun 498(3):487-494. https://doi.org/10.1016/j.bbrc.2018.03. 005

37. Pan J, Lu L, Wang X et al (2018) AIM2 regulates vascular smooth muscle cell migration in atherosclerosis. Biochem Biophys Res Commun 497(1):401-409. https://doi.org/10.1016/j.bbrc.2018.02. 094

38. Ravussin E, Lillioja S, Anderson TE, Christin L, Bogardus C (1986) Determinants of 24-hour energy expenditure in man. Methods and results using a respiratory chamber. J Clin Invest 78(6):1568-1578. https://doi.org/10.1172/JCI112749

39. Parlee SD, Lentz SI, Mori H, MacDougald OA (2014) Quantifying size and number of adipocytes in adipose tissue. Methods Enzymol 537:93-122. https://doi.org/10.1016/B978-0-12-411619-1.000069

40. Schulz C, Fork C, Bauer T et al (2014) SLC22A13 catalyses unidirectional efflux of aspartate and glutamate at the basolateral membrane of type A intercalated cells in the renal collecting duct. Biochem J 457(2):243-251. https://doi.org/10.1042/BJ20130654

41. Cypess AM, Kahn CR (2010) Brown fat as a therapy for obesity and diabetes. Curr Opin Endocrinol Diabetes Obes 17(2):143-149. https://doi.org/10.1097/MED.0b013e328337a81f

42. Cristancho AG, Lazar MA (2011) Forming functional fat: a growing understanding of adipocyte differentiation. Nat Rev Mol Cell Biol 12(11):722-734. https://doi.org/10.1038/nrm3198

43. Geissmann F, Jung S, Littman DR (2003) Blood monocytes consist of two principal subsets with distinct migratory properties. Immunity 19(1):71-82. https://doi.org/10.1016/S1074-7613(03) 00174-2

44. Auffray C, Fogg D, Garfa M et al (2007) Monitoring of blood vessels and tissues by a population of monocytes with patrolling behavior. Science 317(5838):666-670. https://doi.org/10.1126/ science. 1142883

45. Misharin AV, Cuda CM, Saber R et al (2014) Nonclassical Ly6C monocytes drive the development of inflammatory arthritis in mice. Cell Rep 9(2):591-604. https://doi.org/10.1016/j.celrep.2014.09. 032

46. Panchanathan R, Duan X, Shen H et al (2010) Aim2 deficiency stimulates the expression of IFN-inducible Ifi202, a lupus susceptibility murine gene within the Nba2 autoimmune susceptibility locus. J Immunol 185(12):7385-7393. https://doi.org/10.4049/ jimmunol.1002468

47. Vogel H, Scherneck S, Kanzleiter T et al (2012) Loss of function of Ifi2 $202 b$ by a microdeletion on chromosome 1 of C57BL/6J mice suppresses 11ß-hydroxysteroid dehydrogenase type 1 expression and development of obesity. Hum Mol Genet 21(17):3845-3857. https://doi.org/10.1093/hmg/dds213

48. Vogel H, Montag D, Kanzleiter T et al (2013) An interval of the obesity QTL Nob3.38 within a QTL hotspot on chromosome 1 modulates behavioral phenotypes. PLoS One 8(1):e53025. https:// doi.org/10.1371/journal.pone.0053025

49. Vogel H, Jähnert M, Stadion M, Matzke D, Scherneck S, Schürmann A (2017) A vast genomic deletion in the C56BL/6 
genome affects different genes within the Ifi200 cluster on chromosome 1 and mediates obesity and insulin resistance. BMC Genomics 18(1):172. https://doi.org/10.1186/s12864-017-3552-6

50. Stadion M, Schwerbel K, Graja A et al (2018) Increased Ifi202b/ IFI16 expression stimulates adipogenesis in mice and humans. Diabetologia 61(5):1167-1179. https://doi.org/10.1007/s00125018-4571-9
51. Li H, Liu F, Guo H, Zhu Z, Jiao Y (2014) Role of interferoninducible protein 202 (p202) in the regulation of adipogenesis in mouse adipose-derived stem cells. Mol Cell Endocrinol 382(2): 814-824. https://doi.org/10.1016/j.mce.2013.11.006

Publisher's note Springer Nature remains neutral with regard to jurisdictional claims in published maps and institutional affiliations. 